\title{
A NATIONAL DATA SYSTEM ON ELEMENTARY AND SECONDARY EDUCATION
}

\author{
GEORGE HALL, ${ }^{*}$ RICHARD M. JAEGER, ${ }^{\dagger}$ PHILIP KEARNEY ${ }^{\ddagger}$ and \\ DAVID E. WILEY ${ }^{\S}$
}

${ }^{*}$ Washington, D.C., ${ }^{\dagger}$ University of North Carolina, ${ }^{\ddagger}$ University of Michigan and

${ }^{\S}$ Northwestern University

\begin{abstract}
In the U.S., major changes in education information needs have resulted from widespread dissatisfaction with learning outcomes and dramatic changes in decision processes and policies. The inadequate quality of existing information has sharpened demands for improvement. This report, prepared for the U.S. Education Department, recommends a new national information system, with (a) sample micro-records for pupils, educational personnel, districts and schools - public and non-public, (b) coverage of family and community, pupils' educative difficulties, resources, goals, schooling process, and outcomes, and (c) accurate characterization of each state. The system should include state participation options, comprehensive data access and dissemination, and five-year phasing.
\end{abstract}

\section{Changes in Education and Changing Demands for Information}

The most important fact about elementary and secondary schooling in the United States today is that there is almost universal dissatisfaction with its quality. This dissatisfaction, in turn, has begun to force major changes in the educational system, and these changes are taking place within new contexts for making educational decisions. No longer do these decisions fall within the exclusive purview of local school boards and local school administrators. Parents are exploring new alternatives for the education of their children. State officials and public bodies are expanding the range of their actions in attempts to improve the quality of schooling. And information about the quality of education - about the quality of schools, school districts, and state educational systems - has become a priority concern for the increasing array of new policy actors now involved in making decisions that affect the quality of the education being received by the nation's children and youth.

\section{Rising Public Concerns About Educational Quality}

The 1970s and early 1980s saw a growing feeling on the part of the citizenry that many of our nation's young people were not being properly prepared for entry either into col- 
leges and universities or into the American work force. These sentiments perhaps were expressed most visibly in the recent report of the National Commission on Excellence (1983) which contends that ". . . the educational foundations of our society are being eroded by a rising tide of mediocrity" (p. 5). But the Commission's report, in truth, made no new discoveries. Well before the issuance of $A$ Nation at Risk concerns about the serious problems of the schools had been receiving increasing attention from a number of writers. In the middle 1970s, nationally syndicated columnist Neal R. Pierce (1977), writing in the Washington Post captured the growing discontent among the Nation's governors on matters of public education. In Pierce's words:

The hard facts are that in schools from coast to coast, verbal and mathematic Scholastic Aptitude Test scores have fallen steadily since 1963 - almost without regard to whether the school system is poor or rich, center city, suburban or rural. Reputable surveys have shown that 12 of every 10017 -year-old high school students are functionally illiterate, that scarcely 50 percent know that each state has two scnators or that the pres ident can't appoint members of Congress. . No one believes the schools' problems will be quickly or easily solved. But across the nation, the ferment for change is growing rapidly. [p. $x$ ]

The growing ferment that Pierce described produced a number of common themes themes expressed by governors, state legislators, state education officials, education interest groups, and increasingly by parents and coalitions of parents and other concerned citizens. Chief among these themes was a call for a return to the basics, a demand for stricter school discipline, a demand for minimal competency testing, and a growing resentment against an educational establishment that constantly sought more funds but stubbornly resisted external monitoring.

Other journalists also were increasingly writing about the problems faced by the Nation's schools. Robert Benjamin (1981), in the introduction to his book, Making Schools Work, captured both the sense of increasing public alarm over the plight of the schools - particularly the urban schools, and the importance of broadening the stakes beyond those of the professional educator:

The quest was hopeful: What makes schools work well? But it was set against a discouraging backdrop: the persistent failure of this nation's public schools to educate low income students by even minimal standards.

It was a reporter's journey, rather than a professional educator's. It was undertaken with the belief that the benefits of this viewpoint outweigh its limitations, that all of us have a clear stake in shaping the solutions to what may prove to be the most challenging problem facing America's cities in the 1980's. [p. 1]

Concerns about the quality of the Nation's schools also increasingly were being expressed by the business community which saw, in the failures of the schools, serious problems for the national economy and grave threats to the United States' position in the world. The New York Stock Exchange (1982), in its report, People and Productivity: A Challenge to Corporate America, advocated a strong effort to raise business awareness about their stake in the problems the schools were facing: "We must understand that schooling is a longterm investment in human capital, and that productivity suffers when that investment is neglected" (p. 13). In its report, Action for Excellence, the Task Force on Education for Economic Growth (1983), whose membership consisted primarily of governors and business leaders from some of America's major corporations rather than professional educators, argued that:

Technological change and global competition make it imperative to equip students in the public schools with skills that go beyond the "basics."

. . . Mobilizing the education system to teach new skills, so that new generations reach the high general level 
of education on which sustained economic growth depends, will require new partnerships among all those who have a stake in education and economic growth. [p. 9]

By the middle of the decade of the 1980 s, public education had become an object of great concern to a wide array of Americans - to parents, to other citizens, to state education officials, to governors, to state legislators, to broad-based interest groups, to the business community, and to a host of other Americans who now began to see themselves as increasingly important stakeholders in the Nation's schools.

\section{The Changing Nature of Educational Decision Making}

In the opening paragraph, we noted that growing dissatisfaction with the quality of schooling has begun to force major changes in the educational system, including major changes in the contexts in which educational decisions are being made as well as major changes in the cast of educational decision makers. These changes forced an opening up of the decision making process and resulted in almost totally erasing public education's traditional identity as a separable and special governmental operation. These changes resulted in pulling educational issues into the political mainstream; in opening up the system to parents, to the general public, to general government, and to special interests; and in forcing professional educators to integrate diverse segments of the community into the decision making processes of education.

At the local level, the Nation has witnessed and continues to witness a redistribution of the political influence previously held almost exclusively by professional educators and primarily by local school superintendents and local school boards. Parents, teachers, minority groups, students and others have successfully pressed their cases. They have gained access to and have assumed significant roles in the educational decision making process.

But it is at the state level that perhaps the most profound changes are taking place. New configurations of political power have emerged. In state after state, governors and legislators have superceded the traditional custodians of educational legislation and are assuming an increasing role in the decisions about the financing and control of the schools. As one looks across the Nation, one sees that policy decisions about education are more and more being hammered out in legislative halls and chambers, in governors' offices, in state board rooms, in the offices of associations and interest groups, and less and less in the offices of local school superintendents and the meeting rooms of local school boards.

Over the past fifteen to twenty years, the Nation also has witnessed an unprecedented involvement in public education by the federal government - the courts, the congress, and the executive agencies. We now have a cabinet level Department of Education. And despite its traditional minor role in financing education, the federal government has become a significant force. By 1985, federal support for higher education, not including research and scholarship, had exceeded $\$ 8$ billion. At the $\mathrm{K}-12$ level, federal expenditures rose from $\$ 642$ million in 1960 to over $\$ 15$ billion in 1985 - a twenty-three fold increase and a significant amount of money, even if it covers only 7 to 8 percent of the cost of operating the public schools. And the Congress has not been content to play the silent banker, it also has directed how the schools should spend the funds. While recent efforts of the Reagan Administration to return more responsibility and decision making authority 
to the states have achieved some success, it appears that the federal government's involvement in education is not likely to diminish significantly in the immediate future.

Thus, at this time in the United States, we find that the educational policy process is no longer a tightly-knit or closed system. Intervention in the policy process has become generally open to any individual or group who can claim to represent a constituency, who can gain access to information, and who is familiar with the points of access into the system. Nor is the educational policy process monolithic, fixed, or static. Educational decision making has become an evolving, interactive process open to external ideas and influences, involving many individuals and groups, involving all levels of government, and all levels of organization and program administration. And it is not only the locus of educational decision making that has changed. The cast of educational decision makers has been greatly enlarged - parents, other citizens, representatives of interest groups, educators, executive staff, executives, legislative staff, legislators, governors, Congressional staff - all have become participants in the process.

\section{The Catalytic Role of 'A Nation at Risk'}

As the nation approached the middle years of the 1980 s, reform was in the air. Study commissions were being established. States were considering major reform efforts. But it was the Report of The National Commission on Excellence, A Nation at Risk (1983), that truly caught the public's eye, moved education to the 'front burner' as a critical public policy issue, and served as the catalyst for a spate of reform activity across the Nation. Since the publication of $A$ Nation at Risk in 1983, the country has been literally besieged with calls for educational reform, calls that have issued from national, state, and local levels, from public and private sectors, from academe, from business and industry, from parents and other individuals - in short, from virtually all quarters. Governors have created their own committees on excellence, state legislatures have proposed and enacted a bevy of reform statutes, state boards of education have issued blueprints for action, local school districts - often in concert with local business and industrial interests - have established their own reform committees. One observer describes the phenomenon as "a kind of rising Greek chorus of education reform that is sweeping across the Nation."

The reforms, and calls for reform, cover a broad range. In a great many states and locales pupil testing has taken center stage. Merit pay systems and career ladders for teachers have caught the reformer's and the public's eye. The high school curriculum also has become a priority target for reform efforts, most visibly in the Commission on Excellence's (1983) recommendation that all students seeking a high school diploma be required to "lay the foundations in the Five New Basics" (p. 24) - to take 4 years of English, 3 years of Math, 3 years of science, 3 years of social studies, and $1 / 2$ year of computer science. This particular recommendation, coupled with the Commission's call that "significantly more time be devoted to learning the New Basics" (p. 29), have served as an impetus for many states, as well as hundreds of local school districts across the land, to propose and in many cases adopt new high school graduation requirements and extend the length of the school day if not the school year.

Another abiding theme reflected in current nationwide reform efforts is the training and retraining of educational leaders. This theme, in particular, is often woven together with a second theme - joint, cooperative efforts between the education and business com- 
munities. Parental voice and parental choice have become a cause celebre of many of the reform efforts. There is a growing feeling that American society has surrendered too much responsibility for schooling to governmental bureaucracies and professionalized institutions and, thereby, neglected the more human-sized groups, what Peter Berger and Richard Neuhas (1977) have called the "mediating structures" of society - such as families, communities, voluntary organizations, and religious groups.

There are numerous other targets of current reform efforts - revitalization of teacher training institutions, improvement of knowledge dissemination practices, integration of education and technology, better fits between education and employment, to name a few. And as we noted earlier, even though $A$ Nation at Risk served as a major catalyst for the current reform movement that has swept the country, the calls for educational reform and the responses to these calls did not necessarily await the publication of A Nation at Risk. A good many reform efforts already were well underway before the Commission on Excellence sounded its general alarm.

But irrespective of the sources of the impetus for any particular reform effort, what appears central to all of them is an almost universal call for data - data on how students are doing in our schools, on what they are learning, on their levels of achievement; data on how teachers are doing, on what constitutes good teaching, on the mix of conditions necessary to ensure that our professional teaching ranks become filled with "the best and the brightest"; data on curricular programs, on effective instructional practices, on new ways of learning; data on the context in which schools operate, on the climate in the classroom, on family, social and economic environments; data on resources, on the most effective mixes and uses of resources, on resources and equity issues; data on alternative approaches to schooling, on the private sector of schooling, on choice within the public sector.

We see, then, as we enter the final years of the decade of the 1980s, American education - particularly as it takes place in our elementary and secondary schools - deeply immersed in a reform effort similar to what the Nation experienced following the general alarm raised in 1958 by the Russian launch of Sputnik. Whether one fully agrees with all of the cries of alarm and calls for reform now being sounded across the country, one has to acknowledge that American education - particularly at the elementary and secondary level - currently is in a state of ferment and, conseqeuntly, open to massive changes in its traditional modes of operation. Usdan (1985, p. 24), in citing Kirst's attention cycle, contends that we have passed through the stage of "alarmed discovery" and are now in the midst of a second stage of "crisis activity". However, as Usdan further contends, the reform movement can only endure if the effectiveness of specific reforms can be proved. But to demonstrate the effectiveness of the reforms, one needs information substantially different from that which we traditionally have gathered, and that information needs to be provided to a substantially different group of users.

\section{New Users of Educational Information}

In the past, the primary information users were the education professionals responsible for conducting the educational process. These decision makers participated in local information systems focused around day-to-day decisions made by teachers and administrators. Such information systems generally were limited to providing basic data on the local level 
about pupils, personnel, educational services, and finances. Now, however, we are finding that information must be conveyed beyond the boundaries of the local educational agency. Parents need information about the character and quality of the educational alternatives available to their children. The citizenry - local, state, and national - requires and is demanding information about the quality of its schools. The business community - at local, state, and national levels - is calling for systems that will provide quality assurance information on the schools. State officials - governors, legislators, state school board members, officers of state education agencies - require more comprehensive and accurate information on the quality of the schooling being conducted within their purview. Federal officials - from the President through the Congress to the agency administrators - are seeking information on the general condition of American education, as well as on the effectiveness of federal education policies and programs.

We alluded earlier to a growing feeling among the body politic that American society has surrendered too much responsibility for schooling to governmental bureaucracies and professionalized institutions. There is a rising demand for parental voice and parental choice in the education of the young; in many locales, parents have moved to exercise more voice and more choice in these matters. As a result of becoming increasingly important actors in the policy process, parents also have become information users. They have sought information to help them fashion plans for decentralization, school site management, parent advisory councils, and other proposals designed to get around the entrenched school bureaucracy. They have sought information to help them make choices about the schools to which they send their children, choices within the public sector as well as between public and private. But too often the needed information has been lacking. James Coleman (1985), in his invited paper written for the redesign project, argues that federal education data activities can be used to help correct this situation, to augment parental resources by "encouragement and facilitation of parental and community use of information about student performance and school functioning" (p. 17). In Coleman's view, the federal education statistics agency ought to act, in effect, as "a representative of the consumers of education", informing parents of their information rights with respect to both public and private schools, providing to local districts which are so inclined specifications for appropriate consumer information systems, and designing such systems to accompany school choice plans developed for use within public school systems, as well as those that include nonpublic schools (pp. 17-20).

The general citizenry - as well as parents - also have become growing users of information on the schools. They want to know what the schools are doing. they want to know what and how well children and young people are learning. they want to be able to compare their local schools with other schools, their state educational system with other state systems, the Nation's schools with the schools of other nations. They want to be assured that their tax dollars are being well spent. As James M. Banner, Jr. (1985), in his invited paper put it:

For good or ill, the American public now seeks to be assured of improvements in education at all levels, especially in the primary and secondary schools. And, characteristically, it wants information that compares present conditions with those of the recent past and conditions in one jurisdiction with those in others. Yet the plain fact of the matter is that the data available to provide such comparisons is embarrassingly weak. The public is being mislead by their use (pp. 3-4).

The business community, too, has become a user of educational information. It wants 
asurance that the schools are preparing the young "for productive participation in a society that depends ever more heavily on technology, . . . (Education Commission of the States, 1983, p. 9). And the latest entry in the long list of reports on American Education, by the blue-ribbon Committee for Economic Development (CED) (1985), corroborates this contention. Dennis Doyle and Marsha Levine (1985), in a recent article describing the CED report, write that:

There is an opportunity today to forge a new quid pro quo between Americans and their public schools. there will be more money for education when there is more education for the money. The business community (at least, as represented by the CED trustees) stands ready to put its shoulder to the wheel to support public schools - including substantial increases in funding - when the public schools are willing to set and meet the objective of a high-quality education for every citizen (p. 118).

State officials, as education has become more centralized and governance and control mechanisms traditionally left to local school boards have reverted to state school boards and state education agencies, if not to state legislatures and governors' offices, also have become increasing users of educational information. To a great extent the increasing call for and use of education data have been driven by the states' assumption of a more active role in the decision making process; but equal weight needs to be given to rising concerns about educational accountability. Legislatures are increasingly questioning the effectiveness of America's public schools; and increasingly they have assumed a more active role in education decision making. Fuhrman and Rosenthal (1981) argue that “. . . legislatures have taken on the role of pre-eminent education policy-makers in some states; in many others they are at least co-equal partners; and in only a few are they still secondary" (p. 1). As such, legislators have made increasing demands on state agencies for more accurate, more comprehensive, and more timely data on the quality of public schooling. Governors, too, have become ardent consumers of educational information as they have moved to enter the education policy arena and mount their own reform programs. They, like the members of the state legislatures, are no longer content with the traditional education information reports proferred in past years. They want information on the effectiveness, on the costs and the benefits, of the policies and programs mounted to improve the quality of schooling.

Fortunately, in our view, officials in the U.S. Education Department and the Office of Educational Research and Improvement (OERI) view the current climate of reform as an opportunity "to seize the day," to develop the new data acquisition programs that will provide the public the information that it needs and wants, policy makers the information they need to judge the efficacy of the reform efforts, and the educational community the information it needs to monitor these efforts over time. The Elementary/Secondary Education Redesign Project comes at a most opportune time, a time when our long-standing faith in the American public school system is being seriously challenged, a time when serious minded reformers are proposing substantive changes in traditional modes of school operation, a time when the education community has begun to fashion exciting and promising responses to these calls for-eform, and a time when an entirely new configuration of education information and data needs is presenting itself.

\section{Capabilities of Present Education Data Systems}

In the previous section we documented widespread demands for the reform of Ameri- 
can education, and ways state governments, local education agencies, citizens' groups, and business and professional organizations are working to meet those demands. Coupled with demands for reform are new requirements for information on the status, condition, and functioning of schooling in the United States, and for information on education more broadly defined. In this section we examine the capabilities of current data systems to meet these new requirements, and the consequent needs for reform of federal collection and dissemination of data.

\section{The Structure and Content of the Nation's Education Data Systems}

Responsibility for the collection and dissemination of information about education in the United States is fragmented. Much of the information collected is derived from administrative records maintained by local education agencies and schools.

Local Education Agencies. Formal records in local education agencies are usually of six types:

pupil records (e.g., cumulative folders, transcripts);

instructional service records (e.g., curriculum specifications, course schedules and syllabi);

personnel records (e.g., job categories and assignments, certification levels);

financial records (e.g., accounting and payroll records);

records required by other agencies (e.g., health records);

policy records (usually the result of special data collections).

These records are the formal outcomes of 'official' events that occur within the local agency or within schools operated by that agency. When students are enrolled, teachers are hired, purchases are made, grades are issued, or tests are taken, then records are created, supplemented, or revised. Some of these records are placed in separate files and later formally summarized and entered into central record systems. Unfortunately, the content and organization of record systems vary from one local agency to another. This has caused problems as records are transferred from local agencies to other jurisdictions. Inconsistencies in the types and forms of records kept by different agencies produce substantial differences in the memory of data reported by those agencies. Common units of reporting and common definitions are necessary for useful data aggregations of data, and these common elements seldom exist. These issues are discussed at length by Coleman and Karweit (1972).

Records maintained by local education agencies also are fragmented. For example, although students' high school transcripts list completed courses, they usually do not indicate which teachers taught them. And when teachers are related to courses, there is often no way to link this information to the teachers' personnel records.

State Education Agencies. Local administrative records form the basis for reporting information to state agencies. States control the form and content of these records (e.g., The Illinois School Student Records Act - P.A. 79-1108). Usually a state education code spccifics the content and timing of reports. In California, for example, the State Department of Education issues a Data Acquisition Calendar covering state-mandated data collections and reports by local agencies.

One purpose of local agency reports to the states is to determine the amounts of state tax monies local agencies receive. A second purpose is to monitor compliance with the state's 
education code. These reports form the core of the states' information systems about local education. However, this core is often supplemented by special-purpose periodic or ad hoc data collections conducted by the state. These are not integrated into a comprehensive information system. Usually, different subdivisions of the state agency are responsible for different data. Most often, distinct data files are maintained for different purposes. However, as new information technology has become available, some states have begun to design and operate integrated information systems.

The U.S. Department of Education. The Center for Statistics is the Department's agency for the collection, analysis, and dissemination of information about elementary and secondary education. The current data-collection activities of the Center (as of fall, 1985) can best be described as a set of disparate projects, rather than a data system. The Oxford English Dictionary defines a system as "An organised or connected group of objects; a set or assemblage of things connected, associated, or interdependent so as to form a complex unity" (emphasis added). That the current activities of the Center for Statistics do not form a system is amply documented in the public discussion draft of the Synthesis Report (1985) produced for the Center's Redesign Project. Hence our use of "projects" to describe the Center's activities.

The Center for Statistics collects data from two primary sources. The first is a "Common Core of Data" that is reported by states from the administrative records of local agencies and the state's own records. These data are provided annually by every state agency. The Center for Statistics is a recipient and a compiler of the Common Core of Data, and not a proactive collector of the data. Also, the Center does not conduct systematic audits of these data.

The other principal source of Center data is its own sample surveys. These survey data are, almost exclusively, collected by mail using pencil-and-paper questionnaires. Some surveys are periodic (e.g., biennial surveys of schools), and others are occasional (surveys of recent college graduates). In contrast to the Common Core of Data, these survey data are usually obtained from nationally representative samples. These samples support statistical estimates for nationwide populations, rather than state-by-state estimates or comparisons. For some surveys, such as the National Assessment of Education Progress (NAEP), reasonably precise estimates can be computed for regional populations. A concise listing of data collected through the current projects of the Center for Statistics is provided in Appendix C of the Synthesis Report (1985).

\section{The Ability of Current Center for Statistics Data Projects to Meet New Demands for Information}

Data Quality. According to authors of papers for the Center for Statistics Redesign Project, the deficiencies of data collection projects operated by the Center as of the spring of 1985 are legion. The Center data on the nation's systems of elementary and secondary education are claimed by these authors to be:

inaccurate (David, 1985, pp. 2-3; Eubanks, 1985, p. 1; Hawley, 1985, p. 2; McClure and Plank, 1985, p. 1; Murnane, 1985, p. 6; Walberg, 1985, p. 20ff; McDonough, 1985, in a letter);

imprecise (Barro, 1985, p. 16; Harrison, 1985, p. 2; Hawley, 1985, p. 19; Hilliard, 1985, 
pp. 11 and 15; Lehnen, 1985, p. 4; Murnane, 1985, p. 2; Rosenholtz, 1985, p. 2; Selden, 1985, pp. 15 and 17; Thomas, 1985, p. 5; Valdivieso, 1985, pp. 1 and 13);

inadequate in scope and coverage (Banner, 1985, p. 7; Barro, 1985, pp. 2, 4 and 9; Bishop, 1985, p. 18; Eubanks, 1985, p. 2; Hannaway, 1985, p. 1; Hersh, 1985, p. 11; Miller, 1985, p. 1; Natriello, 1985, p. 3; Odden, 1985, p. 5; Peterson, 1985, pp. 11 and 12; Reisner, 1985, p. 2; Scott-Jones, 1985, p. 5; Selden, 1985, p. 1; Thomas, 1985, pp. 2ff.); inappropriate (Banner, 1985, p. 6; McClure and Plank, 1985, pp. 10 and 14); and lacking in timeliness (Berryman, 1985, p. 17; Grant, 1985, pp. 2 and 3; Harrison, 1985, p. 2; McClure and Plank, 1985, p. 14; Reese, 1985, letter).

On the last point, W. Vance Grant, head of the Education Department's Statistical Information Office, compiled a list of the most recently available statistics on various topics. Some had not been compiled for years later than 1975-76.

Judging the accuracy of statistics reported by the Center for Statistics is difficult, since clearly-correct standards are seldom available. Nonetheless, the examples of questionable results cited by Cooke, Ginsburgh and Smith (1985), and Plisko, Ginsburg and Chaikind (1985) raise serious questions about validity. In some instances, problems of definition lead to markedly different reports on purportedly identical variables. Examples include the high school dropout rate ( 27 percent - Center vs. 6 percent - Census Bureau) and Special Education enrollment, where states report as few as 5 percent and as many as 13 percent of their enrolled students in special education categories.

An obvious problem of data quality arises from the Center for Statistics' dependence on the accuracy of reports by state agencies. In such programs as the Common Core of Data and the Vocational Education Data system (VEDS), the Center merely aggregates, compiles, and reports data supplied by state agencies, but does not audit the data received.

Scope and Coverage of Data. Many authors of papers for the Center for Statistics Redesign Project cited inadequacies in the scope and coverage of data, and the inability of the present Center projects to provide information that can be used to compare the condition and progress of education in the various states. The latter point will be considered first.

With the exception of the Common Core of Data, most Center data support estimates for nationwide, and more rarely, for regional populations. Yet education is an activity that is constitutionally reserved to the states and important education policies originate at the state level. The need for statistics that support comparisons across states has been strongly voiced. Lehnen (1985) stated:

National averages and other statistics do not reveal much about the state education systems . . Yet it is the states who will determine the direction and scope of education policy and not the federal government. Without this detail Center for Statistics data will have only limited utility for policy studies within the states.

\section{And the National Governors' Association (1985) noted:}

\footnotetext{
In order to perform education policy setting functions, states need to plan, develop, implement, and evaluate education initiatives . . . national trend data and consistent and accurate data from all states for macro comparison purposes is of key interest . . . samples should be examined to determine the feasibility of expansion to collect data more state specific.
}

In the first section of this report, we described rapid changes facing U.S. education policy. Reports on the quality of American education have called for major reform of resource allocations, curricula, requirements, instructional patterns, certification routes, etc. Many authors of Redesign Project papers document the inability of the current Center 
data-collection projects either to substantiate the need for reforms, or to support an investigation of their effects. Deficiencies cited concerned:

The allocation of educational resources. Data on the allocation of resources among school systems within states, and among categories of students are meagre and outdated.

Investments in and expenditures for education. Expenditure data collected by the Center for Statistics are currently available only for gross categories - "instruction, support services, and non-instructional services" - that mask, rather than inform an accurate picture of the use of resources. Barro (1985; p. 4-5) provides a synopsis of the deficiencies of currently-available data. And Odden (1985; pp 4-5) cites the need for detailed, state-comparable expenditure data by function (e.g. administration at the school system central office level), and by program (e.g., regular education, categories of curriculum such as mathematics, reading, science, social studies, etc., and level of education, such as secondary). Odden notes that such data are central to emergent policy interests both at state and federal levels.

The coverage and scope of curricula. Several authors noted that the Center for Statistics currently collects little information on what is taught in schools. Hawley (1985) cited the absence of data on curricular scope and the level of difficulty of subjects. Cronin (1985) expressed concern that the suggestion for curricular reform contained in A Nation at Risk would lead to an overly narrow curriculum, but cited the paucity of Center data that could be used to document current curricular breadth or curricular reform.

The nature of educational requirements and siandards. Although the 1983 report of the National Commission on Excellence in Education recommended increases in high school graduation requirements, the Center for Statistics does not regularly collect data on such requirements, nor on standards of quality imposed on curricula or student performance. Minimum competency achievement testing is another reform that is poorly understood, and for which impact data are not collected by the Center.

The extensiveness and quality of instruction. As Peterson (1985; pp. 3-5) noted:

To take the pulse of American education, we need to know what students are doing and learning in classrooms in the United States. . . . Following publication of the Nation at Risk report in 1983, many states responded to the recommendations by lengthening the school day, many school districts set minimal standards for the number of minutes that teachers must spend teaching each of the major subject areas during a given week. The impact of these new guidelines on what teachers and students are doing in classrooms has not been assessed.

Peterson also specifies a lack of data on the quality of educational activities. In particular, she notes that a national commission on reading was unable to determine the amount of time teachers spend on important structural components of reading, or to determine the amount of time students spend in silent and oral reading. These concerns are also expressed by Hersch (1985).

The demography of pupil populations. Several contributors to the Redesign Project noted deficiencies in data on the demographics of pupil populations. Hilliard (1985, pp. 4 6) suggests that demographic data are essential to investigations of equity in our nation's schools. He notes that present data neither support analyses of differential allocation of resources nor do they allow satisfactory accounting of the educational experiences of students of different racial and ethnic groups. Although Valdivieso (1985; pp. 11-13) credits the Center with some of the most extensive data available on Hispanics, he cites the 
need for more better-differentiated data on the educational characteristics and participation.

Family and community. Coleman (1985) documents the changing demands placed on schools by changes in family and community structure, including the prevalence of working mothers and one-parent families. To assess the need for school policies that meet these challenges and the schools' success in doing so, Coleman calls for the collection of new contextual information, including data on the schools' relations to students' families and their communities. Usdan (1985) also suggests that data on education must include information on the societal context in which schools operate. He notes the increasing delivery of educational services by agencies and institutions outside the schools, and suggests that information on the extensiveness and quality of those services must be collected.

The characteristics and quality of educational personnel. Perhaps the most dramatic changes in education policy can be seen in states' reactions to the public clamor for better teachers. Most states have adopted new requirements for teacher certification, including the passage of tests of content and pedagogical knowledge. Incentives for joining the teaching profession have been provided through revision of salary schedules, adoption of merit pay plans, and establishment of career-ladder programs.

According to Anrig (1985):

One of the fastest-moving changes in this period of educational reform is in teacher testing. In as little as five years ... testing . . has spread ... to a nationwide trend involving 38 states ...

Again, the Center for Statistics does not provide the kinds of information that must be available to assess these reforms. To understand the need for, and the effects of, reforms in teacher selection, employment, and compensation, the Center for Statistics must collect and report information on the recruitment and retention of teachers, as well as on the quality of the instructional workforce. No such data exist for the nation as a whole or for individual states. Since reform actions differ across states, state-by-state information will be essential.

The outcomes of education. Since the late 1970s, more than two-thirds of the states have adopted minimum competency achievement testing of students. In almost half the states, competency tests are used as a high graduation sanction (Pipho, 1984). Although numerous educational researchers have speculated on the effects of minimum competency testing (see Jaeger and Tittle, 1980) no nationwide data allow us to test these speculations.

In summary, $\Lambda$ merican education is changing rapidly, with new educational policies that affect all participants and stakeholders. To understand the need for policy change, its short-term impact, and its long-term effects, will require a radically improved, and vastly changed, national education data system.

What Should be the Federal Role in Building a National Educational Information System?

\section{The Mission of the Center for Statistics}

On March 1, 1867, the Congress acknowledged the need for a federal agency that would provide the nation with information on education (Kursch, 1965; pp. 11-12). In establishing a department of education (without Cabinet standing) the Congress declared: 
Sec. 1. There shall be established, at the city of Washington, a department of education, for the purpose of collecting such statistics and facts as shall show the condition and progress of education in the several states and territories, and of diffusing such information respecting the organization and management of schools and school systems, and methods of teaching, as shall aid the people of the United States in the establishment and maintenance of efficient school systems, and otherwise promote the cause of education throughout the country.

Sec. 3. It shall be the duty of the Commissioner of Education to present annually to the Congress a report embodying the results of his investigations and labors, together with a statement of such facts and recommendations as will, in his judgment, subserve the purpose for which this department is established.

Thus, from its very beginning, the purpose of the Departmen of Education was the collection, analysis, and reporting of information on the condition and progress of education, to help states and local school systems improve their effectiveness to inform the Congress on the status of and returns to the federal investment in education. Through time the agency devoted to these tasks became the National Center for Education Statistics and now (beginning in 1985) the Center for Statistics.

In the General Education Provisions Act of 1974, as amended (Section 406(b), 20 U.S.C. 1221e-1), the mission of the Center was updated and made more specific:

The purpose of the Center shall be to collect and disseminate statistics and other data related to education in the United States and in other nations. The Center shall:

(1) collect, collate, and, from time to time, report full and complete statistics on the condition of education in the United States;

(2) conduct and publish reports on specialized analyses of the meaning and significance of such statistics;

(3) assist State and local education agencies, including State agencies responsible for postsecondary education, in improving and automating their statistical and data collection activities;

(4) review and report on educational activities in foreign countries; and

(5) conduct a continuing survey of institutions of higher education and local education agencies to determine the demand for, and the availability of, qualified teachers and administrative personnel, especially in critical areas within education which are developing or are likely to develop, and assess the extent to which programs administered in the Education Division are helping to meet the needs identified as a result of such continuing survey.

\section{Assumptions Concerning Federal Participation in a National Educational Information System}

A central assumption of this proposal for a national educational information system is embodied in its title - that it be a national information system, not solely a federal information system. This objective can be realized only by recognizing that education is principally reserved to the states and often delegated by them to local agencies. If information is to stimulate and guide educational reform, educators and citizens and policy makers at all levels of government must help design a national information system to serve their needs.

Although the federal government has had profound effects on U.S. education in the last three decades through policies concerning diverse educational issues, managerial responsibility for elementary and secondary schooling devolves to the federal government infrequently - primarily in American Indian reservation and Defense Department schools. The management of the education most students receive is reserved to the states and, through state statutes, delegated in major part to local education agencies. Therefore, state and local agencies need management information as well as information on the effects of their policies, while the federal government, apart from its need for data on the operation of federal education programs, needs policy information. 
The distinction between information required for management and that required for policy analysis is not superficial. To manage effectively, an agency must have comparable information on every administrative unit within its purview. To assess the need for, and the effects of, educational policies, information on representative samples of units will suffice. Also, the content of a management information system would be somewhat distinct, but far from entirely distinct, from the content of a policy information system.

In an effective national information system, the needs of data users at all levels of government, in addition to the needs of consumers of education, would be considered. The information system proposed here is designed to meet the policy information needs of the citizenry and federal government, while stimulating, supporting, and complementing systems designed to meet the needs of state and local agencies. It explicitly seeks to meet some needs of consumers of education.

Experience has shown that any attempt by the federal govermment to impose a uniform information system, designed to meet all federal and state needs for information, is doomed to failure. Users at all levels of government must decide for themselves what information they need and what they will use. The time for cooperative development of a national educational information system, designed and maintained by a coalition of concerned policy-makers and educators at federal and state levels, is now.

The Council of State Governments (in their 1985 position paper on the Redesign Project) stated:

What remains [for the Center for Statistics] is the problem of identifying the best means of providing useful
statistical information to the [state-level] political decision makers within their unique environment.
Given that information is 'that which reduces error', we should conclude that providing better, more use-
able, statistical information to these important political actors will encourage improved educational policy
decisions... in the same way that providing better information to SEA and LEA leaders has improved
their capacity to make better decisions.

In an era of federal retrenchment, a proposal for federal leadership in the development of an integrated national educational information system might appear anachronistic. Yet such a leadership role is clearly within the statutory authority of the Center of Statistics. The General Education Provisions Act of 1974 (Section 406(b), as amended in 20 U.S.C. 1221e-1) defines as a part of the Center mission:

(3) assist State and local education agencies, including State Agencies responsible for postsecondary education, in improving and automating their statistical and data collection activities.

An assumption underlying this proposal is that federal leadership in developing such a national information system is an essential part of the Congressionally-defined responsibility of the U.S. Department of Education.

This plan is based on the assumption that the Department of Education is willing to modify its current activities and to invest the resources necessary to develop an adequate education statistics program. In particular, we assume the following:

(1) Current Center projects can and may be eliminated, replaced, modified, or left untouched to the degree necessary to effect an adequate system for collecting, analyzing and reporting data on the condition of education in the United States.

(2) An effective national information system need be constrained by neither the current funding level of the Center for Statistics, nor the present administrative structures of the U.S. Department of Education and the Office of Educational Research and Improvement. 
(3) Such a system need not be constrained by the presently defined mission of the Center for Statistics.

(4) A new system should be designed explicitly to meet well-defined needs for information on education; that is, the data content and functional organization of the system should be determined by a thorough and explicit analysis of the needs of data users.

\section{An Expanded Mission for the Center for Statistics}

Many contributors to the Center for Statistics Redesign Project view the 1974 statement of the Center's mission (defined in the General Education Provisions Act, as cited above) as inadequate, and, as less comprehensive than the original charter of the Department of Education in 1867. Although the 1974 mission statement defines specific responsibilities for the Center for Statistics, it does not empower a single federal agency with sole authority and responsibility for informing the nation on education. As a result, the Center for Statistics does not do enough and other federal agencies may do too much. Unnecessary duplication, lack of coordination, and excessive respondent burden are well documented in the papers prepared for the Center's Redesign Project.

The mission we propose for the Center for Statistics would make it the federal agency with authority and responsibility for collection of data concerning education in the United States. Other agencies with specific needs for regulatory data on education or with unique capacity or expertise (such as the Office for Civil Rights, other agencies within the Department of Education, the Departments of Labor, Commerce, Agriculture, and Defense) might collect such data, but would have to coordinate with the Center for Statistics.

Our position on these issues is consistent with that advanced by the Council of Chief State School Officers (1985);

\footnotetext{
We strongly urge that the function [of the Center for Statistics] be a true statistical center that assumes the major responsibility for coordination of the collection, assembly, analysis and dissemination for that sector of society under its purview, namely education.

The Secretary of Education would be required to make a clear and committed designation that the Center would have responsibility for coordination of statistical data collection and analysis activities across the Department of Education regardless of organizational lines and/or bureaucracies. This assignment would also require that the Center be charged with promoting the integration of the numerous data collection activities conducted by other federal agencies (Department of Agriculture, Bureau of the Census, Department of Labor, et al.) and related private agencies (National Education Association, American Council on Education, and the testing industry) to minimize burden on respondents and to develop increased standardization of terminology.

The coordination role would include: (1) first and foremost, the coordination of the various activities currently under development in NCES (e.g., CCD, VEDS, NELS-88); (2) expansion of the system to include those other data collection activities of the Department of Education (e.g., Special Education, Chapter I of ECIA, Chapter II of the Math and Science Act); and finally, (3) establishment of out-reach activities to other agencies to ensure appropriate federal and national coordination. Included in this function would be defining a common set of data elements across the spectrum, coordinating collection of all statistical data, developing efficient collection and dissemination systems (in conjunction with users and providers), seeking out current needs for educational information, and providing assistance, both technical and financial, to the respondees and users of educational data.
}

Obviously, expansion of the Center for Statistics mission to that of a 'true' statistical center would require commensurate expansion of capability to support such activity. Realistic investments in personnel, facilities, equipment, and funding would have to be made.

In sum, the mission we envision for a federal education data center would be: 
(a) coordination of all collection, analysis and reporting of data on education by the executive branch of the federal government;

(b) to the degree possible, collection of data on education required by other agencies of the federal government;

(c) meeting the needs of the citizenry and federal policy-makers for information on the condition and status of education in the United States, by developing and maintaining an integrated national educational information system;

(d) providing leadership, information, and assistance to state governments and local agencies in the development of complementary educational information systems for purposes of management and policy analysis;

(e) effecting such research, quality control and auditing procedures as are necessary to ensure the precision, quality, and integrity of the information provided by a national educational information system.

\section{Designing a New National Educational Information System}

From our perspective, an educational information system must be designed to fulfill the needs of those who will use the information to enhance the quality of the educational experiences for which they have authority and responsibility. The fact that educators have such authority and responsibility as their central concerns implies that their needs must be a central focus of the system. The fact that citizens and public officials also have such authority and responsibility implies that their needs also must be served. And the fact that parents have such authority and responsibility implies that their information needs must be served as well.

By addressing whose needs must be served we also inform the issue of what kinds of information they should receive. If the information is to serve the needs of those who have the responsibility for decisions affecting the quality of education experienced by pupils, then it must allow assessment of the quality of the educational system and the parts of that system which affect its quality. Thus, only if we have a conceptual framework for the assessment of educational quality can we make appropriate choices about the information to collect and the form in which to make it available.

Such a framework should also lead to a more cohesive system, i.e., an information system which allows relevant linkages between its components so that better assessments can be made of the effects of changing one part of the system on the other parts. Also, since any information system requires allocation of limited resources, a conceptual framework allows one to set priorities within the system to achieve maximum benefit from the resources available.

In designing a new data system, one needs to answer several critical questions. These include:

(1) What information should be collected and how should it be organized? This question addresses not only the 'contents' of individual information elements, but also their form, i.e., fundamental linkages between elements that allow or prohibit their use for specific purposes. A full answer to this question would completely specify the form and content of a data base.

(2) How should the information be collected? This issue encompasses not only the methods of data collection, but also the categories of persons and administrative records 
which will provide the data. Sample design, timing of collection, and provision of standards of data quality — including mechanisms for assessment and control - are also key issues.

(3) How should it be made available for use? This latter question breaks down to: Who should receive what information, in what form, when, and at what cost? These issues address data transmission processes among those responsible for collecting the data and maintaining the system as well as information flows linking external users into the system. As such they include specification of records to be transmitted, timing and frequency of transmission, aggregations and analyses to be performed and reported, regulation of access - including timing of data releases, provision of privacy and security constraints, availability of micro- versus aggregate records, the costs of access and who should bear them.

In the remainder of this section, we outline such a conceptual framework, draw from it implications for the design of a data base (Question 1, above), and discuss a framework for access and use of the data contained within it (Question 3, above). We postpone discussion of data collection (Question 2, above) to the section 'The New National Data System: Configuration, Implementation, and Consequences'.

\section{A Conceptual Framework for Describing an Educational System}

An educational system is an organization which converts resources into education services for pupils. From our perspective, one can specify public education as a system at the level of classroom, school, district, or state. These form a nested set of educational systems, with varying and changing responsibilities for governance and policy formation. Private educational systems typically have fewer organizational levels.

Ultimately, the success of an educational system - regardless of organizational level is predicated on its outcomes. An exclusive focus on achievement, however primary as a public signal of the failures and success, is not sufficiently informative to improve that system (Harnischfeger and Wiley, 1982). Learning, and its educational manifestation, achievement, occur in and are supported by other parts of the pupil's life than schooling.

Children live in widely differing circumstances. Some belong to families where parents value and are able to suppport school learnings, other parents neither realize the importance of these learnings, nor have the resources to undergird or augment their children's schooling. Thus, schools are confronted with wide variations in the educative difficulties they face.

Assessing and improving the quality of education requires considering student achievement in relation to these difficulties, and evaluating and modifying the educational efforts which are made through the process of schooling. To merely focus on achievement means to praise those educational units that draw students from educationally advantaged backgrounds, i.e., schools and districts of high socio-economic levels. This is a disservice to those who educate disadvantaged students.

A conceptual model. In order to apprehend educative processes, we must rely upon a conceptual model. This model may be simple or complex and it may be implicit or explicit, but its existence is a prerequisite to any understanding of the effectiveness and quality of schooling. Our conceptual framework - presented below - for describing an educational system focuses on the school because it is at the level of the school that educational ac- 
tivities take place and that pupils participate in them. This framework is drawn from Harnischfeger and Wiley (1982).

By this primary focus we do not mean to imply that all primary educational decisions and actions do take place or should take place at the level of the school. Centrally important decisions about resources and their allocations, educational goals, and educational activities and programs take place at the state level - in governors' offices, legistatures, state departments of education - and at the district level as well. We do mean to imply, however, that once these decisions are made and constraints are imposed, much of the process of implementation - i.e., using the allocated resources to create educational experiences addressing desired outcomes - takes place at the school. Thus any framework for constructing a comprehensive description of educational systems must begin with the school and expand from it to the other levels of the systems.

Fundamentally, schools and the communities they serve differ in several important ways:

Family and Community Environment. The families and communities served by different schools differ in significant ways. They differ in the resources available in the homes of the pupils for support of their schooling and they differ in types and levels of aspirations parents have for their children. The family composition of the community affects the attitudes, values, and goals of a pupil's peers. All of these form the context within which schools can educate their pupils.

Educative Difficulty. Schools are faced with differences in levels and types of educative difficulties with which their pupils present them. Some present handicaps or limited proficiencies in English. Others come with limited levels of prior learning. Thus, pupils who enroll in some schools enter with cognitive accomplishments and capabilities, motivations, and out-of-school environments and resources which made educative efforts easier and less complex than those in other schools.

Resources. Schools have available to them different levels of monetary resources and different amounts and kinds of non-monetary resources, such as volunteer time, donated supplies and equipment.

These resources are exchanged, allocated, and configured as a teaching staff, facilities, educational materials.

Goals. Schools aspire to distinctive goals. For example, some public secondary schools design their entire curriculum around post-secondary career paths which primarily begin in selective colleges and universities, while other schools, e.g., 'vocational' ones, may focus their whole program around immediate job entry to skilled and semi-skilled occupations.

Process. Schools offer educative experiences for which they require or encourage pupils' participation. These include work experience, homework, and extra-curricular activities as well as in-class experiences. Schools also structure these experiences with different standards. These standards influence the pursuit of goals with different expectations for performance, differing time allowances for accomplishment, and differing criteria for selection into subsequent experiences.

Schools also differ in the types and amounts of participation of their pupils in these educative experiences as well as in the range of experiences made available. These variations include differences in selection, participation, and completion of educational programs, course work, and homework as well as differential school attendance.

Outcomes. All through the schooling process, to the conclusion of secondary schooling 
and beyond, schools differ greatly in the goal-relevant accomplishments and achievement of their pupils. These include cognitive capabilities, credentials, and career and life paths generally.

None of these areas of distinctiveness can be neglected if we are to understand schooling in ways that carry meaning for those who participate in it and are concerned about it and its consequences. School outcomes may differ by intent as well as by the efficacy of programs and activities. Schools, school districts, and entire school systems are presented with considerable variations in the levels of preparation, handicaps, and other educative difficulties that their pupils bring to the schooling process and these have profound consequences for outcomes. And schools and the larger systems within which they are embedded really do differ in their effectiveness. Thus it is vital

to describe, against a coherent conceptual frame, each of these differences in a cohesive fashion, as well as

to attempt to sort out the reasons for differential outcomes against the structure of their origins.

Figure 7.1 displays such a conceptual framework. It focuses on the schooling process, distinguishing teaching activities from pupils' exposure and participation in the resulting educative activities. And it traces these aspects of the process to their origins: prior and contemporaneous characteristics of pupils, community and family expectations, curricular

Background

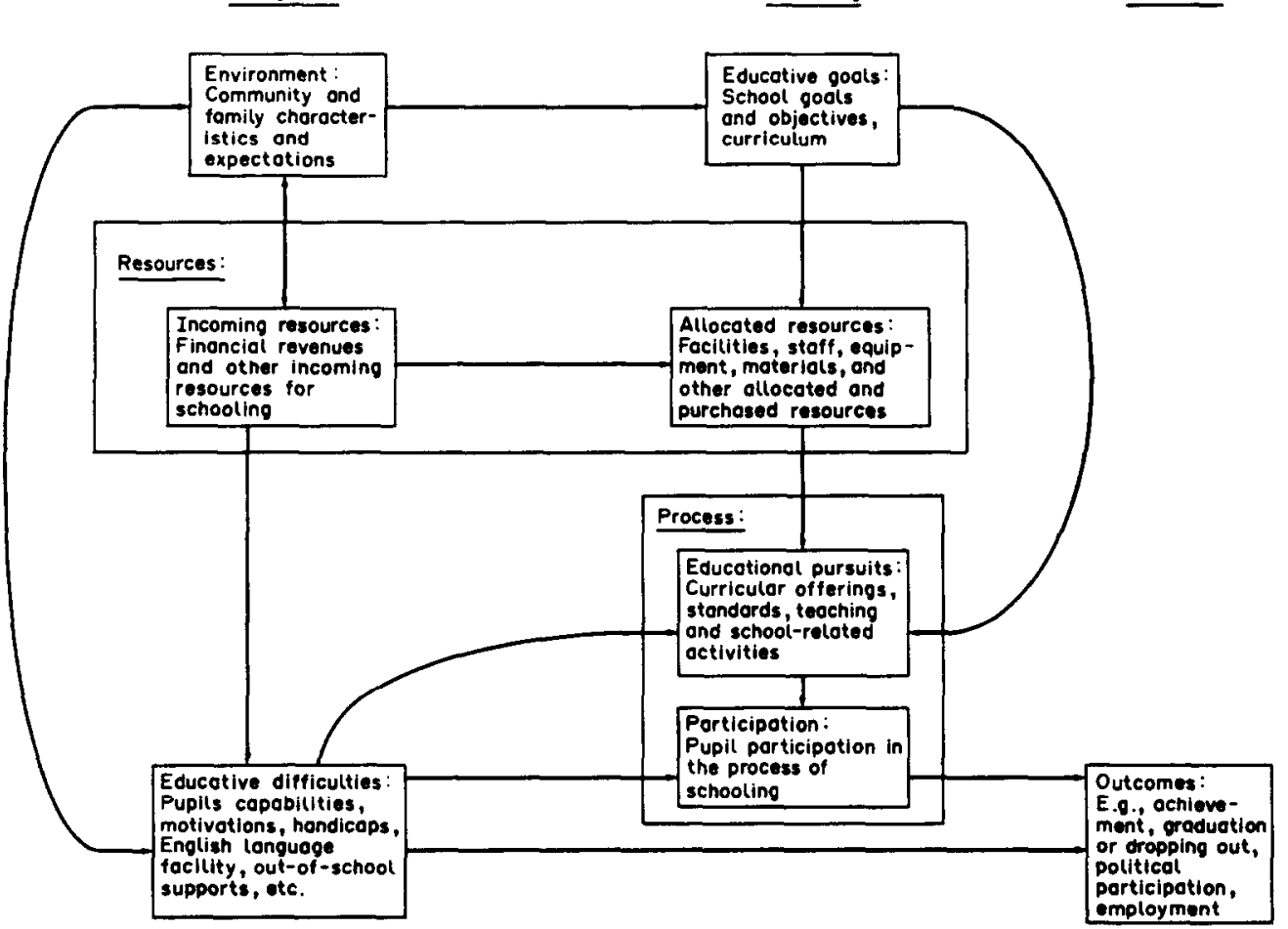

Figure 7.1 A conceptual frame for the schooling process. 
goals, and resources, as well as linking them to their consequences.

The intent of this figure is to clarify that cducative difficulties and goals must be accounted in order to assess the quality of a school system or an individual school. Since some schools must exert greater and more costly efforts in increasing pupil participation than others, the factors which influence the degree of effort required must be accounted if that effort and the resulting 'quality' of the educative process are to be adequately diagnosed. Similarly, the desired outcomes or goals of the educational system affect the kinds of educational experiences offered pupils. Thus, schools which focus solely on narrow or atypical goals may produce learning outcomes which either advance tested achievements relative to non-tested ones or seriously skew them. Much of this effect will depend on whether the test content is broadly defined, balanced, and clearly articulated to legitimate educational goals.

Within the context of school quality assessment and its bearing on school improvement, this framework treats goals, educative difficulties, and resources as pre-conditions (or background elements) for process description and outcome interpretations. We may then explore the implications of this framework for meaningful and valid comparisons of schools and school systems.

What are the implications of this framework for the design of a new national educational information system? First - and foremost - in order to validly assess the quality of our educational systems, the data collected must be comprehensive. That is, these data must measure the background conditions and the current difficulties pupils present to their schools, and they must assess the goals pursued by the schools and the resources available to address them. They must record the experiences mounted - i.e., the educational services offered to and required of pupils - with these resources and they must account pupils' participation in these experiences and the outcomes resulting.

Second, in order to help improve the quality of education received by pupils, the linkages among these aspects of schooling must be revealed. For example, we need better information about how resources are used to mount educational experiences; i.e., what are the abilities of the teachers who conduct these experiences? What are they paid? How are educational activities and experiences created out of facilities, materials, and the time and effort of educators? We also need better information on participation. How are pupils with differing backgrounds and characteristics selected for participation in particular experi ences? What are the actual rates of participation of various types of pupils in these experiences? Finally, we need clues to the effectiveness of tracks, programs, and experiences especially for pupils with differing characteristics. What are the outcomes - in both the short-and long-runs - of these pupils' participations.

\section{The National Data Base}

As we discussed above, a statistical information system has three aspects: a data base, processes for the collection and entry of information into the base, and processes for making the information available for use. At this point we will proceed to draw on the implications of this discussion for the content and structure of the data base. Subsequently, we will 
explore some of the alternatives for getting this information to those who can use it for their decisions and then discuss options for data collection and data base creation.

A conception of the data base. The core of a data base is its content and organizational structure. The content of a data base consists of the definitions of the data elements included. The structure of the base consists of the records containing these elements, the files containing these records, and the linkages among them.

Data elements characterize specific entities and the elements which characterize a single such entity are often kept together. These collections are termed records. For example, pupils might be characterized by features of their home environments, the courses they have taken, or their tested achievement. Similarly, teachers could be characterized by their credentials or their employment and salary histories. Districts, schools, educational activities, and equipment could all be entities for which files are constructed. Local education agencies maintain files and records with many of these kinds of entities as the focal unit.

Thus, an accounting system is a collection of records of transactions. An employee file contains records for each employee. A district level school file contains records on each school in the district. A high school catalogue or student handbook contains 'records' on each course offered. And a trancript file contains records for each pupil in the school. We term these 'basic' files: microrecords.

Up to this point in time, the statistical information in the Common Core of Data has not included microrecords for pupils, for educational personnel, or for school programs or activities. Other data bases do include microrecords. Examples are the pupil records of High School and Beyond and the National Assessment of Educational Progress. The Common Core of Data consists primarily of summary or aggregate records. Thus school districts count pupil and employee records to create enrollment figures and personnel distributions and these new summary records are further summarized by the states. Similarly, accounting transactions are summarized into ledgers and financial reports which are transferred to summary records for transmittal to state and federal data bases. Thus, for example, the school district records in the Common Core of Data contain some school district level microdata - e.g., identification number, address, fiscal and control status, type code, etc. - but the primary data contained in these records are summaries of pupil, employee, and school microrecords maintained at the school or district site.

One primary recommendation of this report is that the federal data base contain microrecords for pupils, personnel and material resources, and educational activities. It is not advocated that the federal collection of these microrecords constitute censuses of pupils, personnel, and activities. Although, within the data collection alternatives outlined below, some states may wish to explore this option in the reconfiguration of their own management and policy information systems. Thus, the structure of the data base being proposed is an integrated collection of sampled microrecords.

Such a data base structure is mandatory if the process of conversion of resources into experiences outlined in the previous subsection is to be traced. The critical policy decisions now being made at the state level are specifically intended to influence and constrain the critical decisions in this conversion chain. It is this chain of decisions which is the key to the improvement of educational quality and which constitutes the focus of the new educational reforms. Only microrecords for personnel, pupils, and activities can produce the kinds of analyses and reports necessary to inform and evaluate these new policy initiatives.

For example, linkage of course taking to achievement - in the sense of tabulating the 
achievement test results for students with different patterns of course taking - is impossible without student microrecords containing both course taking and achievement data. Separate school, district, or state aggregates of course taking and achievement do not permit such reports. Similarly, tabulation of the qualifications of the teachers who teach specific kinds of courses is impossible without integrated microrecords linking teachers and their qualifications to the particular courses they teach.

File structure and content. In the rest of this section we outline the kinds of files we envision constituting the national data base. These files fall into three categories.

First, there are within-school microrecords. At the minimum, we recommend that these microrecords constitute a collection of such records in each of a sample of schools. An open issue is whether such collections should be censuses in some or all sampled schools. We also recommend that such records be contained in at least three linked files: pupil, personnel, and educational activity.

Second and third, there are school and district-level records. Under some of the data collection alternatives discussed later in this report, these records might consist of samples rather than censuses as at present. Also, within-district microrecords are necessary. At the minimum, samples of personnel records for non-school based district personnel are required for a sample of districts so that summary estimates of personnel figures do not omit personnel who are not assigned to schools. Financial records may also be collected within districts - with coverage of sampled schools - so that human and material resource files can be constructed. To keep records of manageable size and acceptable accuracy, we also recommend that many of the currently collected school- and district-level aggregate counts be calculated by aggregating the within-school microrecords in the central data base rather than continuing the collection of the aggregates themselves at the school-and district-site levels. This procedure would allow standardization of data definitions at the microrecord level, which, in turn, will assure the validity of aggregate comparisons. As we discussed earlier, a central problem for state-level comparisons currently is the lack of commonality in the definitions of particular data elements by districts and states.

(1) Within-school microrecords.

(a) Pupil files. These files should be extracted from the various pupil level records maintained at the school site. We envision records for pupils with the following categories of data elements:

(i) family background and home environment,

(ii) special needs and educative difficulties presented to the school,

(iii) educational outcomes: achievements, graduation, dropout, honors, etc.

(iv) educational participation: attendance, activities, pursuits, experiences, e.g., grade level, courses, program participation, etc.; these will be linked to the activity files, below.

(b) Personnel files. These files will include records on the educational personnel attached to the school. They would include information on: position held, responsibilities, compensation, credentials, academic and employment history, participation in educational activities mounted by the district. These latter elements will be linked to the activity files, below.

(c) Activity files. These files will include records on the educational activities mounted by the school. These activities might be defined at different levels of aggregation, e.g., Chapter 1 participation, grade level, semester-class or course, counseling services, special activity, program or course of study. The records in this file will be linked to both the personnel records of employees who participate in their provision and the pupil records of 
participants.

We note here that the number of data elements in each of these files could be quite modest. For example, we estimate that the microrecord file for an individual employee required to reproduce the current Common Core of Data aggregates for educational personnel need contain no more than five data elements.

(2) School files. These files will contain records for each school in the data base. These records will include characteristics of the community served by the school as well as organizational and structural characteristics of the school which are not aggregates of pupil, personnel, or activity records and which are not selections of district records. Examples of data elements are those currently included in the Common Core of Data, however, we envision additional information, such as information concerning the community served by the school.

(3) District files. These files will contain records for each district in the data base. Data elements will include characteristics of the community served and organizational and structural characteristics of the district which are not aggregates of within-school microrecords or school records. In addition, categories, sources, and amounts of in-kind and fiscal resources flowing into the district will be recorded, together with source imposed constraints on their expenditure. Expenditures will also be included in three ways: districtwide amounts in expenditure categories will be recorded at a finer level of detail than currently, micro expenditure data will be collected for district-wide expenditures, and micro expenditure data will be collected for sampled schools in the district. To supplement these kinds of expenditure data, it is possible to construct parallel files on resources purchased. Thus, for example, district level personnel files can be constructed for non-school based personnel and facilities, equipment, and materials files can also be created. Again, it is important to create these files for resources which are not school based as well as creating school-linked records from central district files. Of special importance to these latter records are equipment and educational materials.

Feasible tabulations, analyses, and reports. Two categories of analyses and reports are feasible with a data base of this kind. First, there are counts, summarizations and aggregations of data elements. Thus, enrollments, achievement test averages, course taking patterns, and home environmental characteristics are available by processing individual pupil records to the level of the school, the district, the state, and nationally. Similar summarizations are possible for educational personnel, other purchased resources, educational offerings and resource inflows. At this level of analysis, the current information in The Common Core of Data would be reproduced from the new data base. However, substantial additional information would also be available which is currently unavailable. This includes not only characterizations of pupil background, special needs and difficulties, program and course participation and achievement, but also teacher characteristics and qualifications, and characterizations of the programs, experiences, and courses offered by the school or district.

Second, the microdata files are linked. This allows relational tabulations and reports to be created. In addition to tabulations such as course-taking linked to achievement - a cross-pupil data element tabulation referred to above - cross-file tabulations are possible. For example, teacher characteristics can be linked - via course taking - to pupil performance. Thus, a three way tabulation could be produced from linked microrecords of teacher characteristics by course type by achievement. Such tabulations would form important information for consideration of certification or graduation requirements policies. 


\section{The Use of Educational Information}

Earlier in this report, we distinguished between managerial and policy uses of information. Managerial uses of information primarily relate to ongoing decisions necessary for an organization to carry out its mission. The nature of these decisions is predicated on the established mission and specific goals of the organization, and the specific organizational structure created to carry these out. Policy decisions relate to modifications in the mission or the specific goals of the organization, and to changes in its organizational structure. The essence of an information system - underlying both the content of the information included and the uses to which that information can be put - rests on these decisions, the information needed to make them, the constraints placed upon them, and their consequences.

Schooling decision processes. In our conceptual frame for the schooling process (above), we set forth schema for characterizing schooling, together with its preconditions and its outcomes. What was not explicit in that schema was the kinds of decisions which must be made in order to carry out schooling. It is these decisions which require information. And it is this information which must be collected, organized, and distributed before it can contribute to these decisions. We will first analyze the decisions made at the local level, mentioning some of the constraints which narrow decision options. We will then look at the state policy role, exploring the nature and methods by which states influence local education decisions. This will then allow us to discuss the kinds of data needed by particular decision makers and the form that it should take. Finally, we will outline some of the policy options for information distribution.

Decision processes in local education agencies have many participants; school board members, administrators, teachers, parents and students. If we follow the schema of Figure 7.1 , resources flow into the school, are converted to staff, facilities, equipment, and materials, which - in turn - are converted into educational pursuits. Pupils participate in these pursuits and, as a consequence, learn, accomplish, and achieve. Each stage of this conversion process - (1) monetary to (2) human and material resources to (3) offerings and activities to (4) pupil participation - involves fundamental educational decisions. These decisions constitute the schooling process within the constraints imposed by existing policies and available resources.

To fully create the schooling process, four basic types of decisions must be made: (1) budgetary, (2) hiring/purchasing, (3) curriculum/instructional, and (4) participation. These are illustrated in Figure 7.2.

Budgeting decisions allocate incoming resources - primarily monetary - to budget categories. These allocations are cleary constrained by the total resources available from all sources. The decisions are made by elected and appointed governing boards or public officials on the basis of information and recommendations provided primarily by administrators and they incorporate the schooling goals held by the participants.

Hiring/purchasing decisions are made by administrators using the budgeted resources. The purpose of the budget is to formally constrain these decisions to follow the goals and priorities of the budget makers. Stated policies (formalized goals) guide administrators in making decisions within budgetary guidelines. Also, the availability and prices of personnel and products with particular characteristics limits these hiring and purchase decisions.

Curriculum and instructional planning take place within the limits imposed by employed personnel and the facilities, equipment, and materials purchased by the local agency. 


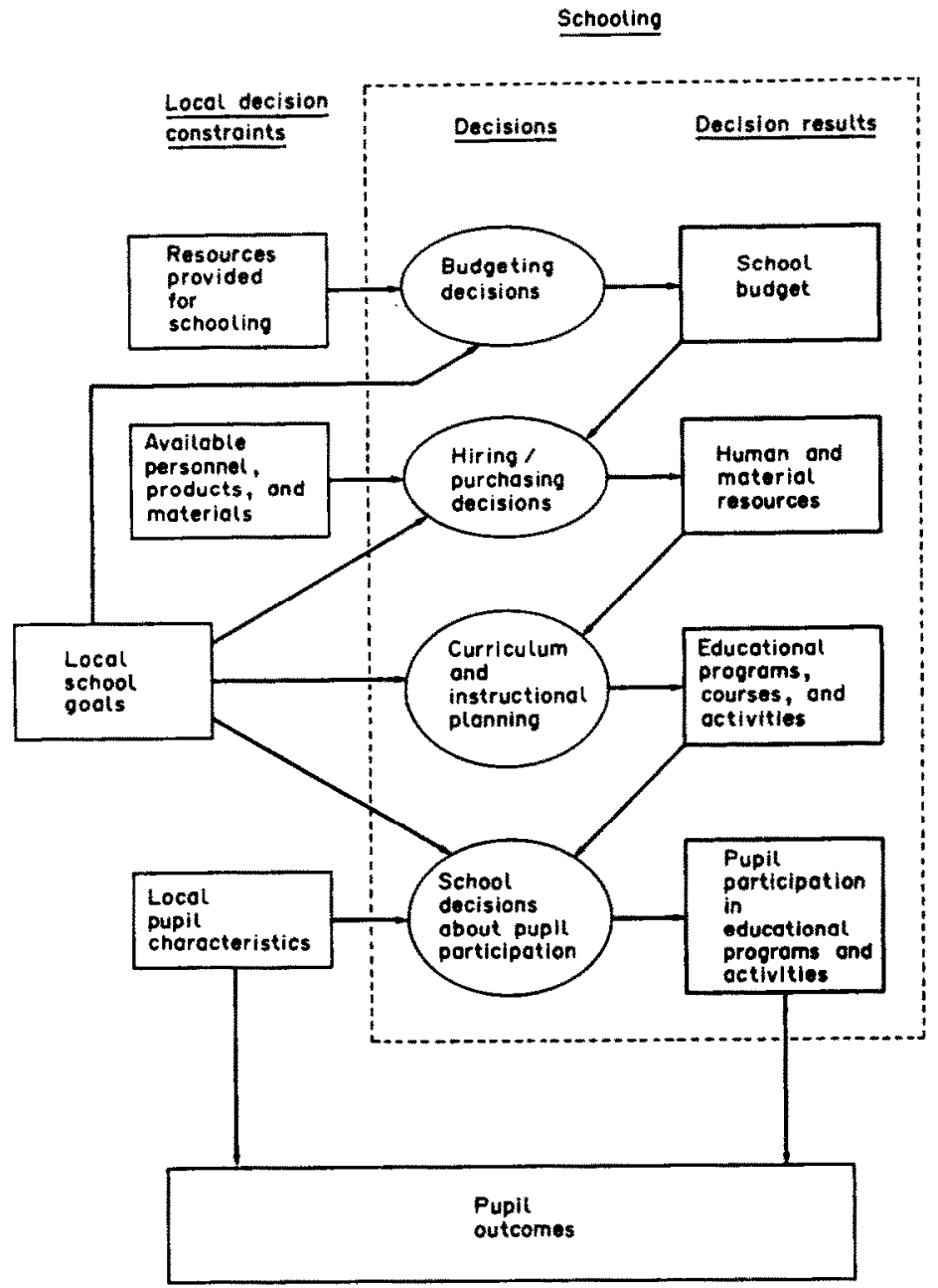

Figure 7.2 Local resource, program, and pupil decision processes for schooling.

These planning decisions further implement school goals insofar as they are internalized by the personnel making them or are codified into formal policies. The planning creates educational activities - programs, courses, units, etc. - and organizes, staffs, provides facilities and materials for, and sequences them.

Participation decisions are constrained by the available offerings. If a program, course, or unit is not offered, a pupil cannot participate in it. Participation decisions are made by teachers, counselors, administrators, parents, and pupils. Many of these decisions are jointly arrived at, but all are made subject to school policies about eligibility for participation. Most of the eligibility policies have formal elements based on past or present pupil characteristics such as grades, test scores, legally structured definitions of linguistic proficiency, handicap, or prerequisite experiences. 
Finally, these experiences, together with what the pupils bring to them, produce learning and achievements, which precurse the subsequent outcomes of schooling.

By using this schematic portrait of local schooling decision processes, we do not mean to imply a linear chronological and causal order. Clearly, for example, some curriculum decisions can be made before the hiring decisions necessary to implement them are made and some hiring may take place before budgets are formally approved. We do imply, however, a logical order. This logical order permits us to trace the flow of resources as they are converted into pupil experiences and thus to analyse the decisions which produce these conversions. The evidence produced at the local level to inform these decisions thus forms the local information base which can be used to create data for state and national information systems. Also, as the decision processes are constrained by policies - formulated at both the local and state levels - a conceptualization of the kinds of decisions and their interrelations helps to define both the content of potential policies and the kinds of information useful in formulating them, i.e., it provides criteria for a national educational information system.

Information for policy. We now turn to state policy making. The purpose of state educational policies is to influence the actual experiences of pupils and via these experiences to affect the learning, achievements, and subsequent life paths of these pupils. The only way in which such policies can have these effects is by influencing the decisions of local educators. These policies - state laws, regulations, formal guidelines - generally provide resources, contingent on specified events or occurrences, or require or prohibit local agency actions. The may also attempt to modify the context within which decisions are made. In any case, they constrain or attempt to constrain local decisions.

In Figure 7.3 we exhibit some of the effects of state policies/laws on local decision making. The left part of the figure - the row headings - lists some of the decision contexts and decisions displayed in Figure 7.2. The column headings list some common types of

\begin{tabular}{l} 
School context \\
\hline or decislon \\
\hline Decision \\
context \\
Senool gools \\
Resources for \\
schooling \\
Available personnel. \\
products and \\
moteriats \\
Decision \\
Budgetary decisions \\
Hiring/purchasing \\
decisions \\
Curriculum ond \\
instructional \\
planning \\
Pupil \\
participotion \\
decisions
\end{tabular}

State legistotion/policy

Legistated School Curriculum $\begin{aligned} & \text { Speciol Certificotion Assessment Groduation } \\ & \text { population } \\ & \text { schooting finance mondotes } \\ & \text { purposes }\end{aligned}$
$\begin{aligned} & \text { programs } \\ & \text { obillty }\end{aligned}$

Figure 7.3 Direct effects of state policies on local schooling decision processes. 
state laws and policies. The entries corresponding to a paired row and column indicate whether the particular policy or law constrains a specific type of decision or modifies a decision context. Thus, for example, certification rules constrain local hiring decisions and might also affect the pool of individuals considering teaching careers. Another example, might be the effect of new graduation requirements on pupil decisions about course taking, school decisions on course offerings and teacher hiring, and budgetary allocations.

These examples also indicate some of the primary data needs of those who formulate and influence educational policy at the state level. At the minimum, information is needed which not only characterizes the outcomes of local decisions, i.e., information about the budget, about the human and material resources hired and purchased, about the educational programs and activities offered, and about participation. Information is also needed about how these outcomes were produced, i.e., how monetary resources were converted to human and material resources by expending salaries and purchasing products, how these resources produced courses, programs and activities by consuming materials and the time of educational personnel with particular skills and characteristics, and which pupils participated in which activities.

This framework focuses on two essentials: (1) the decisions made by parents, pupils, teachers, and other professional educators about the conduct of and participation in actual educational experiences; and (2) the constraints imposed by policies - state and local on these decisions. If the policies are to be effectively formulated, the knowledge base about the decisions must be relevant, comprehensive, and accurate. This perspective forms the basis for the design of a national data base.

We note here that an information base intended for regulatory or managerial purposes overlaps but is not identical in concept to one focusing on policy. A managerial information system might be less comprehensive in content if existing state policies address only limited aspects of educational decisions. but, since state laws and regulations affect each school district, it is mandatory that equivalent information be collected for all of the state's districts if conformity to law and policy is to be monitored. Thus, policy deliberation on some topics might require more extensive information on a smaller number of educational units than management or regulation. Similarly, federal education policy relates to the same local educational processes and decisions that local and state policies address, even if the modes of impact are distinct. We believe that this implies that the conceptual framework for the information to be collected is compatible for state, local, and federal policy information as well as for state management information. The fundamental differences have more to do with information priorities rather than with the basis for specifying relevant types of information.

Local, State, Federal uses of policy information. The primary use of a national educational information base of the kind we propose here is for educational policy, not management information for educational systems.

It should inform policy at the local level by providing standard comparative data on the central aspects of schooling so that informed assessments of local circumstance, using local data can be validly accomplished. The data base should support this by allowing a rich, but standard variety of contextual and process information so that schools and districts can compare themselves to others who are in similar circumstance. This implies a technical assistance and information effort on the part of the Center for Statistics which would enable local educational units and groups of parents and citizens to collect data similar to and comparable with federally supplied information. 
It should inform policy at the state level by providing comparative, standard state information which would allow states to assess the processes and outcomes of their own systems against appropriate contrasts in other states and localities. It should also provide parents, citizens, and public officials of the various states with a minimally standard characterization of their educational system to be augmented by state data oriented toward statespecific educational goals and policies. It should inform policy at the federal level by providing representative information on the context, process, and outcomes of schooling in the United States. This information, in addition to characterizing the fundaments of the nation's schooling efforts, may incorporate additional features related to the success of federally-supported educational programs and defined national educational priorities.

\section{Access to the Data Base}

Issues in targeting access to information. One of the most important (and most neglected) aspects of statistical policy is priorities for access to information. A clear focus on local, state, and federal needs for information directed toward central policy decisions at each level is critical. Policy information cannot be confused with management information if the role of the national information system as a resource for public debate and policy formulation is not to be compromised. Local policy decisions can only be enhanced with a federally-maintained policy-oriented data base if contextual information allows differentiation of data reports and if guidelines for collecting and assembling comparable, local data are provided. State policy information can be undergirded with a standard core for state use and normative comparison.

An assessment of existing information transmission channels would clearly exhibit major blockages in information flow, in terms of existence of channels, and in the match of the information content and format to the users needs. The Center must create an information base on the actual and potential use of the information contained in the national data base and create an ongoing mechanism to set and maintain statistical priorities for access.

Of particular importance at the present time is the timely availability of relevant information for public discussion, policy formulation, and legislative and administrative action at the state and local levels. With the refocusing of educational policy on state-wide educational reform, new mechanisms for the targeting, presentation, transmission, and retrieval of microrecords, aggregate statistics, and analyses based on a federally maintained national data base are mandatory. And how such information is channeled to parents, interested groups, and public officials is a fundamentally new problem to which federal attention and resources must be allocated.

Existing modes of information transmission and data availability. Statistical agencies have a variety of tools for transmitting information to potential users. Our impression is that because of the lack of information and policy concerning data access, some of these modes may be currently underutilized by the Officer of Educational Research and Improvement. Such access methods may be categorized in the following manner:

(a) Published information

(i) periodic publication of basic data series: in the Center, the main current vehicle for this mode is the Digest of Education Statistics; 
(ii) social indicators: periodic reports, topically organized, from a variety of sources; the Center's vehicle for this is the Condition of Education;

(iii) topical reports: focused reports on single topics of public or policy interest; this mode is not commonly used by the Center;

(iv) press releases.

(b) Machine readable files

(i) public use microrecords;

(ii) machine readable summary files;

(iii) on-line access to data base.

(c) Response to special data requests

(i) specially-constructed, user-designed, machine-readable files, e.g., microrecords, aggregate or summary files;

(ii) user-requested - printed or microfiche - tables;

(iii) user-specified statistical analyses.

Each of these modes of access is currently being used by at least one federal statistical agency, but several are not part of the Department of Education's access and distribution system.

Goals for a system of information access and distribution. The system of information access and distribution is a central policy matter for any government agency maintaining a data base. As we discussed earlier in this section, such a policy involves "who should receive what information, in what form, when, and at what cost." Above, we outlined how recipients (i.e., users) of information are linked together and to the data base - both by the modes of access supported by the government agency and by the secondary channels connecting the initial information recipients to others.

Thus, the tasks of the agency prerequisite to the formation of an information policy are to (a) specify and prioritize information recipients and users; (b) determine which information is most useful to priority recipients; (c) determine what form such information should take in order to be most useful; (d) determine how the utility of this information depends on the timing of its receipt; and (e) assess how alternative modes of access and transmission determine which users receive what information, in which form, when.

On the basis of these determinations and assessments, the agency can then establish a policy for allocating its available resources to the variety of modes of access and transmission in the light of their likely consequences for the actual receipt of the information. A major part of this policy would be an apportionment of the costs of access between user and agency. Historically, one successful effort of the Census Bureau has been a shifting of portions of the access cost to the user. In the case of the Office of Educational Research and Improvement, major users of the information have been other governmental bodies. As we expand this to include public discussion and debate, this imposes a materially different context on the question of cost apportionment than in the case of primary use by the business community in the case of the Census Bureau.

The most important issue we raise here is not the content of the information policy which the Office of Educational Research and Improvement and the Center for Statistics must establish. It is the necessity of actually establishing one. Until such a policy is formulated, there is no basis for designing a distribution system or allocating the agency's limited resources to the activities supporting that system. 
The New National Data System: Configuration, Implementation, and Consequences

\section{The Configuration of the System}

We propose a fundamentally new national data system for elementary and secondary education. Our proposal differs in structure and content from present education datacollection activities of the federal government, the states, and local education agencies. Only a fundamentally new system can produce essential data for the nation and the states that are correct, accurate, precise, timely, comparable, and useful. Our proposal may appear costly, demanding, and complex, and will require a long-term commitment from the federal government and the states, but we believe there is no alternative. We have reached this conclusion following an intensive and careful review of recent changes in education, consequent new demands for information, the capabilities of present education data systems, the appropriate federal role in a national data system, and the fundamental characteristics of a responsive data system.

Our proposal is fundamentally different because:

(1) the content of the data system is derived systematically; it is based on a clear conception of what education is, and how education operates in the United States;

(2) the structure of the data system provides linked data elements, data files, and data records; data are collected about and maintained for individual students, teachers, schools, and school systems;

(3) data provided by the system will enable principal policy-makers and other information users to understand the context, processes and outcomes of schooling in the United States.

Further, our proposed data system is characterized by:

(1) state representative samples of public and non-public schools for every state;

(2) a necessarily high level of state and federal cooperation;

(3) a coordinated set of federal and state collection efforts;

(4) a data base which will provide new data to policy makers at all levels of government as well as data for education research.

The proposed program would provide - via core samples and supplementary data collections based on them - all data presently collected through all current Center for Education Statistics projects concerned with data on elementary and secondary education. This includes the longitudinal survey program, the National Assessment of Educational Progress, the Common Core of Data, the Vocational Educational Data System, and the several discrete sample surveys of teachers, private schools, and so forth.

In total, our recommendations are that as follows.

(1) The Center for Statistics should create a national data base of microrecords for pupils, educational personnel, districts and schools, both public and non-public.

(2) The national data base should

(a) incorporate relational linkages among files,

(b) cover family and community environment, educative difficulties of pupils, resources, goals, schooling process, and outcomes,

(c) accurately represent the nation as a whole and the individual state educational systems which compose it and, therefore,

(d) permit accurate comparisons of state educational systems.

(3) This data base should form part of a comprehensive national education information 
system incorporating;

(a) options for state participation in data collection, and

(b) a comprehensive system of data access and dissemination.

(4) The system should be phased with a planned schedule of development and partial implementation leading to full implementation within five years.

'Designing a New National Educational Information System' laid out the conceptual base for the system, including its data base design, its potential utilization, and justification of its content, form, and relevance. Below, we address issues of alternate modes of data collection, research and development issues, costs, phasing, and the benefits of such a system to the nation.

\section{Data Collection}

A basis for cooperative data collection efforts. The proposed information system is based on three elements:

(1) A cohesive, comprehensive national data base;

(2) An information access and distribution system; and

(3) A data-collection system.

We have proposed, above,

(1) A framework for defining and organizing the data base; and

(2) A set of goals and criteria for creating a newly comprehensive system of access and information distribution.

In this section, we identify some alternatives for state participation in the collection of data for the new national data system. These alternatives have varying degrees of integration with newly-emerging systems of policy and management information at the state level. We also propose a new mechanism for cooperative engagement with state departments of education, in forming the new national information system.

Alternatives for state participation. We envision data collection as a joint federal-state responsibility. However, every state may not choose to participate in the same fashion. Some states may see little advantage - at least in the short run - in greatly modifying the nature and extent of the management and policy information they collect. Others may see considerable benefit in a federally-assisted revamp of their entire information system. Most states may be willing to make important changes in the definitions and modes of collection of information helpful to them in their policy and management decisions without fully integrating their systems with the new national system.

States choosing complete integration would collect the requisite information from pupils, parents, teachers, schools, and local education agencies and forward the data required for the national data base to the Federal center. At the other extreme, states may not choose to participate in the system at all. For these states, data would be secured via an integrated set of surveys that are:

(1) federally-conducted, and

(2) parallel in content, structure and timing.

Common requirements for data collection. The key characteristic of the proposed data collection system is not the manner or mode of state participation. In each state it is the form, content, and accuracy of the data collected which are central. Data must conform to the requirements of the national data base. In order to obtain - for each state - such data, some important common provisions are necessary. These include: 
(1) Identical microrecord data elements will be required for pupils, staff, schools, and local education agencies in each state.

(2) The records will be derived from probability samples of all students, staff, schools, public and private.

(3) The school samples will provide samples of local education agencies as well as sampling frames for samples of staff, students, families and communities.

(4) These sample frames will also provide the source of sub-samples and super-samples for conducting other integrated surveys.

(5) Regardless of the source, data will be collected under sampling and quality control rules and procedures promulgated by the Federal center.

(6) Requirements for security and confidentiality will be developed jointly between the center and the states. Federal legislation may be required.

(7) State and local systems will participate with the Federal center to develop a uniform core data set to be provided for each state.

(8) Data collection (or capture) will be scheduled to coincide with the important milestones of the school year.

(9) The periodicity of the data collection will be determined by the Federal center with the cooperation of the state systems.

A framework for state participation in the system. The level and type of state participation can follow a large number of alternatives. The choices made by each state will depend on

(a) the current information system in the state,

(b) the state's assessment of its emerging information needs, and

(c) the costs to the state of the participation alternatives.

The minimum requirement for a national educational information system is that the data from each state be comparable. This, in turn, requires that the data definitions - i.e., the specifications of each data element - be identical from state to state. Thus, if a state is to participate actively in the system, it must adopt data element definitions which conform to those specified for the national data base. If this is not done, there is no basis for national/state cooperation and the Federal Center for Statistics must take on the exclusive responsibility for data collection in those states.

Assuming that common data definitions are established, states have quite distinct existing systems upon which to base cooperation. These systems - as discussed above - have

(a) managerial or regulatory components; typically school district censuses requiring transmission of data necessary to monitor conformity to laws and regulations and allocate funds;

(b) policy components; often sample surveys of outcome or process information.

Because of this, the type and extent of potential cooperation with the national information system depends on the following.

(1) The structure and format of state data collected for policy and management purposes. Primarily, this depends on whether the state now collects - or perceives the need to collect - microrccords on pupils, staff, or activities within schools. Without a current focus or perceived need to collect policy or managerial information of this type, state/national integration of data collection cannot be extensive.

(2) The commonality of state and national needs for data of particular types. If there is little overlap in the data elements desired for state policy and management deci- 
sions - on the one side - and the data elements required for the national data base - on the other - there will be little basis for a cooperative endeavor.

(3) The willingness of the state to integrate its own separate data collections and collaborate on data collection activities with the Center for Statistics. To the extent that most or all state data collections could be articulated and integrated with the collection of national data - i.e., common data forms, times of collection, personnel - a common, cost-effective data collection effort (either state or federally managed) would be feasible.

In order to clarify some of the issues relating to mode and extent of national/state cooperation on data collection, we have tried to spell out some of the features at the two opposite extremes of national/state cooperation. The first - which we term Alternative A assumes no cooperation, i.e., the Center for Statistics takes on full responsibility for data collection in a particular state. The second extreme - which we term Alternative B - assumes maximal cooperation and integration of the state information system with the new national system. We anticipate that most modes of cooperation will fall between these two extremes, at least in in the initial stages of the new system.

Alternative A: Federally conducted sample surveys. Under all of the alternatives, the data records will be produced from an integrated set of parallel, consistently timed, state representative sample data collections of individuals and administrative records. Under Alternative $\mathrm{A}$, this will take the form of sample surveys conducted by the Federal Education Data Center. In each state the Center would select a probability sample of schools that will provide the basis for any other samples which may be required. This could include samples of students and staff, families of students, and school districts. In addition to public schools, a probability sample of private schools would be included in the system. Therefore Alternative A provides for the content, sample design and data base organization of the new education data system. This section describes the critical data collection elements which describe the full Federally managed system.

The sample. As noted above, the samples for the new system will be state representative. The samples will, however, conform to probability design so that it will be possible to examine various organizational constructs and geographic units other than states. For example, the resulting data file could be subdivided to focus on urban schools in a particular state or group of states; predominantly minority schools may be examined; students or teachers with certain characteristics could be examined separately. The principle limiting factor would be the size of the subsample under study.

The sample design for the surveys should provide for sample rotation so that a particular school might be in the sample for only a few years. Each year a subset of the schools could rotate out of the sample and be replaced with another. Although some large or special schools may be permanently included in the sample with certainty, the number of certainty schools may be kept to a minimum. However, this rotation scheme could introduce some disturbances into the data. Biases might result when schools remain in the sample for more than one series of interviews. The Center should anticipate this possibility and develop a research program which would examine the data from each subset separately.

Questionnaires and other instruments. Under this alternative, data will be supplied directly to the Federal Data Center or its agent from the survey site. Various methods would be used to collect data. Whenever the subject matter permits, direct face to face interviews would be conducted. Other methods such as mail or telephone interviews may be used as appropriate. 
The Center will develop the methods to be used for each survey and will design the collection and control instruments accordingly. This will require an extensive research and development effort along with a full program of testing. Every effort to determine the validity of responses to the collection instruments should be undertaken at this time. Response burden, cost, and timeliness must also be considered when the instruments are being designed to find the least burdensome and costly way to produce valid and timely data.

Each document will be the basis of a microrecord in the final system and as such should allow for the kind of flexibility needed to assign survey units to categories according to the Center's definitions. For example, according to The Center for Statistics' staff, at least one state does not classify an excused absence as a true absence; with the collection of summary data, this would present either a comparability problem or a problem of dual record keeping. Using a microrecord approach, the questions for a particular pupil, on the sample day, in the sample school, should ask whether the student was physically present (de facto) and if not, whether the absence was 'excused' (de jure). The part of the pupil questionnaire addressing these issues might appear as follows:

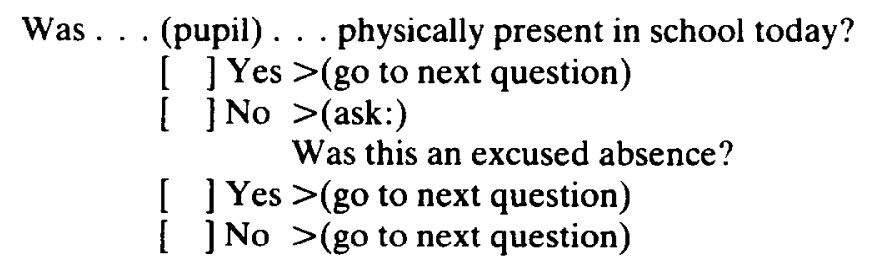

Aggregating these two pieces of information for each pupil in the school or state education agency, the Center may sort out this relatively simple definitional problem.

The data for each pupil would also include the basic characteristics of the pupil - age, sex, race, course information, grade average, test scores and other information which will provide demographic data, performance information and other information about the pupil which when aggregated will provide extensive information about all pupils. Further, the pupil information will be related to that of the pupil's teachers, his or her school, and the local education agency to provide a complete picture of the educational system. Because the development of the forms, documents, and linkages is not simple, however, an extensive research and testing program will be needed. The designer of the pupil microrecord will have perhaps dozens of such issues to confront.

Similar issues will have to be considered for the microrecords for staff, schools, communities, local education agencies, state education agencies, and any other unit of sample to be included in the new system. The Center will require a unit to develop the microrecord forms, questionnaires, or schedules. That unit will have to work closely with the states (and to the extent necessary with private schools or school groups) to determine the detailed questions needed, and to examine definitional differences between different state and local systems. Although these tasks are not casy, there arc many precedents within the Federal government; most of the Census Bureau's work involves the development of questionnaires to produce microrecords. Similarly the Bureau of Justice Statistics, the National Center for Health Statistics and others have extensive experience in dealing with these issues. In the final analysis, standard questionnaires to produce microrecords in the hands 
of highly trained personnel should substantially reduce problems of non-comparability and improve data quality in general.

Quality Control. 'Garbage in garbage out' has become a cliche in the computer age; nevertheless its truth has never been disputed. It is essential that the Center develop procedures to prevent 'garbage in' at each stage of the process. If the new system is to be effective, quality control procedures must be introduced at the time the survey instruments are being developed. There should be rigorous pilot studies and pretests of all of the instruments and all of the procedures to be employed in the field collection.

'Hot houses' should start the process. This is a simple process in which convenient possible survey subjects are asked to respond to potential survey questions. Pilot studies are more formal and typically involve a purposive sample of potential survey respondents. The pilot should uncover more subtle types of problems with the instruments. The pretest should be designed to begin to identify measurable statistical problems with the instruments, the procedures and even the sample; validity questions should begin to be addressed at this stage. Frequently, there must be repeats of any or all of these pre-enumeration activities. Even after all of this testing has been performed and analyzed and the instruments have been put in to use, problems with the questionnaires and procedures will become evident. A constant monitoring program must be established to determine whether the instruments had an intitial defect, whether there has been a measurable biasing effect of pre-enumeration or whether the 'world' has changed.

Alternative A uses interviewers to collect much of the data directly; there must be the establishment of qualification standards for new interviewers involving appropriate tests or other selection devices along with a system of initial supervisory field observations. After new interviewers have become qualified they will still continue to be observed on a systematic basis to ensure that the survey's procedures are being followed. The Center should also develop a system of regular re-interviews in which supervisory personnel will re-interview a small systematic sample of all completed work. Acceptable error levels will have to be determined. Any interviewer whose work fails re-interview may be retrained, terminated or dealt with in other ways as appropriate. The re-interview sample will also provide a basis for estimating some of the non-sampling error.

Since data will be received directly by the Center or its agent, the Center will be responsible for all data processing, including coding, data entry, editing, weighting, and developing the data base. All of these procedures must also be subject to rigorous quality control. Samples of coded materials will be subsampled and the coding verified. Similar steps will be taken for data which are keyed or otherwise encoded.

Organizational issues. The responsibility for data collection lies with the Center. It can opt to undertake the collection directly by acquiring field staff and data processing capability. However, the cost and development times sharply limit the practicality of this option, particularly in the short term. Several commercial contractors already possess the technical and logistical capacity to carry out this work, however Federal procurement policies make it difficult to develop the long-term relationships which would be desirable for program development and data consistency over time. An option would be to ask another Federal agency to undertake the survcy serics under a reimbursible agreement. Under such an agreement, the Center could build a long-term relationship which would permit the development of integrated surveys which would respond to the changing needs for education statistics. Although Hill (1985) states that "contractors can usually get better respondent cooperation than federal agencies can", the reverse has been true of those Fed- 
eral agencies which are clearly identified in the public mind as statistical collection agencies. This is particularly true of the Burcau of the Census which continuously has response rates for its reimbursible surveys as high as 95 percent.

Even though it is likely that the Center will contract out the data processing, it should have a staff capable of preparing specifications for data processing, weighting, and any other technical procedures.

Respondent cooperation. In order to obtain respondent cooperation and to keep the aggravation level at a minimum, the Center will have to take several positive steps. For example, it should carefully communicate its rotation policy to the schools so that they will understand the relatively short term nature of their commitment. Moreover, the Center will have to develop a program through which at least the sample schools receive preliminary reports of the data collected for their statistical area so that they will be able to make comparisons with similar schools. It would be useful for the Center to develop a package which would show individual schools how to utilize data in their own planning and development efforts. Perhaps a subcommittee of the consortium discussed below could assist in the development of such a document. The Center must also be responsible for keeping respondents apprised of future survey visits with information about the content and the timing of each inquiry.

Alternative B: Integrated state policy and management information systems. Several states are in the process of developing integrated state-wide policy and management information systems. Some of these states may be interested in providing data to the Center through these systems. This would be particularly desirable if certain conditions are met. First a state would have to agree to provide an identical set of data elements for each school in the sample and the local education agency associated with each school. The federal data base would require an integrated set of microrecords on a state-representative sample of schools. In designing a state policy and management information system, to be integrated with the national system, states may wish to explore options with respect to (1) census versus sample survey modes of data collection and (2) different levels of integration with their own systems. In any case, the states would have to agree to provide the data on a schedule which is consistent with the processing and publication schedule of the Center.

In the discussion above - Alternative $A$ - we treated issues related to the design of questionnaires and other instruments and to the quality control of the data collection activities. These issues are also central to a data collection system fully integrated with the state management and policy information needs. The same thorough pilot testing and control modes are required. However, these must be developed jointly by the Federal center and the state.

Because the proposed system is to some extent modular, there could be a variety of possible state participation modes. At one extreme a state could provide all of the data required for the entire system, including test and other survey information, to the other extreme in which a state would not actively participate at all. Some states would have a census of all of the adminstrative record information in the system, while others would only maintain the data for the Federally defined sample, depending largely on whether the system is to be used for management information or policy information.

There would be no restrictions on any state's system as to supplementary data elements and sub-systems it may wish to develop. A state would, however, have to provide to the Center only data for the schools in a sample and only those data elements requested by the 
Center. While it might be easier for some states to provide a computer 'dump' of all of the data in its system, it would not be appropriate for the Federal Center to hold all such data in its computer.

Interested states would ask to supply machine readable data to the Center. It would be the responsibility of the Center to determine when a state system had reached the point where its data were complete, consistent, and accurate enough to enter the system directly.

The quality control requirements of direct state data entry into the Center's statistical program would have to be rigorous. Annual audits of a random sample of schools would be part of the program; some individual schools would also be included with certainty if there was any indication of previous problems with data from that school. The Center would have to retain the authority to modify or discontinue a state's direct participation if the quality control procedures indicated serious data problems.

\section{A Mechanism for Cooperative Engagement}

In order to develop the detailed design for the new national data system, the Center, working through the Chief State School Officers, should establish a consortium of all states and develop an agenda for identifying specific information elements and data elements required for the system. The Center should also appoint a number of other members to the consortium, including representatives of local education agencies, academia, and other users concerned with information about the educational system. The consortium should also have a say about the method in which the data base is organized and what data, in what form would become available.

It would be foolish to believe that a body representing this large a constituency could do the detailed planning required for this effort. There would be an obvious need to develop working groups to address specific issues. for example, several states are in the process of developing state level integrated information systems; each is designed to provide the specific data needed for state purposes. In order to foster the development of compatible systems, the Center should attempt to organize a working group of the consortium consisting of states already developing such systems, along with other states interested in similar development. Since in general the systems would be integrated, it would be essential for local systems to be represented. This would facilitate the exchange of information among the states and the development of alternative models which could feed the national data base.

Although the Center would have the responsibility for staffing the consortium and establishing working groups for the various technical issues which will have to be addressed during the development of the system, the total input to the Center should more than compensate for the cost of staffing.

\section{Development and Phasing}

Research, Development and Pilot Testing Issues

Requirements for research needed to develop critical elements of the new data system. Most elements of the national data system we have proposed can be developed using exist- 
ing survey and measurement technology. However, other elements will test the current state of the survey and measurement art, and will require intensive research and devclopment. For example, our proposed system requires microrecord information on a variety of educational outcomes, including but not limited to, achievement test data. To secure such data while adequately controlling the respondent burden imposed on individual students will require the development of new, highly efficient outcome measures and new approaches to the use of matrix sampling. As a second example, our proposed system calls for timely production of policy-relevant analyses that are responsive to immediate and particular requests from the broad array of information users, including policy makers in all branches and at various levels of government, as well as the new constituencies described in detail in 'Changes in Education and Changing Demands for Information'. Considerable research is needed to develop mechanisms that will enable the Federal Center to meet these immediate and particular requests for information with timely, valid, and responsive policy-relevant analyses. Research is needed in such areas as verification of the requestors" rights to data access, mechanisms for rapidly and accurately building relational analyses using data stored on the basis of distinct file structures, methods for providing users with a variety of alternative relational analyses, and methods for assessing the relative utility to policy makers of such alternative analyses.

Provision of adequate time for data system testing and verification. Because many features of the data system we have proposed are novel, extensive testing and verification of mechanisms for data collection, data aggregation and storage, and information retrieval will be required. Such testing will require a continuing commitment by the Federal Center for Statistics, and the continuing cooperation of state and local education agencies over a period of years. Such agencies must acknowledge and agree that no element of the data system will be used operationally until it has been thoroughly tested and its quality has been fully verified, regardless of the sense of urgency that pervades present efforts to provide information on the nation's education systems.

Cost and personnel requirements of various phases, by level of government. In any national data system on elementary and secondary education, a large portion of the dollar outlay and personnel costs of developing and maintaining the system would be borne by the Federal Center for Statistics. This would be true at all phases of development. In particular, the costs of necessary research and development at the national level would be borne entirely by the federal government, as would the costs of testing and verification.

As we discuss extensively below, a variety of alternatives exist for state participation in a new system. The state personnel requirements associated with a national education data system would depend almost entirely on a state's chosen level of participation. And, to the extent that a state chose to integrate its data systems with the national data system, it would share in the cost of developing the national data system. Such cost sharing should be balanced with the relative benefits accruing to the parties involved.

The ongoing cost to the federal government would depend strongly on the number of states participating extensively in the system. If the majority of states were to integrate their management and policy information systems with the effort and participate in the joint setting of standards and procedures for collection of core national data, the continuing cost to the federal treasury would consist of fiscal transfer to states, technical assistance, data base maintenance, analysis, and dissemination services. Thus, after develop- 
ment costs were absorbed, ongoing federal expenses might not be materially greater than currently budgeted amounts. If on the other hand, few states were to fully participate, continuing costs might approach those of a state-by-state expansion of a scaled down version of the National Assessment of Educational Progress or a similar expansion of the baseyear of a national longitudinal study to all states and additional grades.

Dollar outlay costs and personnel costs incurred by local education agencies would depend on the degree to which they chose to integrate their own data systems with the national system and, to some extent, on the degree to which their state chose to integrate its data systems with the national system. These alternatives are discussed below. If neither the state agency nor the local agency chose to integrate their data systems with the national system, the dollar outlay and personnel costs incurred by a sampled local education agency would be negligible during the development of the national system, and would not be substantial once the system became operational. In a state where the state agency chose to integrate its data systems with the national system, data for state management purposes would be collected from every school and local education agency in the state, and local education agencies would have to bear any consequent increased costs to meet the state's data needs. Efforts should be made to minimize - on a continuing basis - such cost increases.

\section{Development and Phasing of the Data System}

Development and phasing of the federal component. We propose that the federal component of the national data system be developed in distinct phases encompasing a five-year period. Phases would be distinguished by specific calendar periods. Within each phase, the specific categories and subcategories of data elements that compose the national data system would be at different levels of development. Data elements would differ in terms of their availability for operational use and the level of their aggregation. Some data elements would be objects of research and development; other data elements would have advanced to a field testing and verification stage; still other data elements would have been tested and verified in earlier phases, and would be available for operational use; $a$ fourth category of data elements would not yet be available in any form. In addition, some data elements would be available initially only from aggregate records, while others would be available in the form of microrecords. The phases would also be distinguished by the numbers and types of data elements that could be linked across data categories and data files, as microrecords become available for operational use.

Categories of data. The categories and subcategories of data that will compose the national data system will be drawn directly from the conceptual model described in 'Designing a New National Educational Information System'. The major categories include: environment (community and family characteristics and expectations); incoming resources (financial revenues and other incoming resources for schooling); educative difficulties (pupils' capabilities, motivations, handicaps, English language facility, out-ofschool supports, etc.); educative goals (school goals and objectives, curriculum); allocated resources (facilities, staff, equipment, materials, and other allocated and purchased resources); educational pursuits (curricular offerings, standards, teaching- and school- 
related activities); participation (pupil participation in the process of schooling); and outcomes (achievement, graduation or dropping out, political participation, employment).

Calendar periods. We propose that the first phase of development, following the establishment of the consortium described below, begin on July 1, 1986 and extend to December 31,1986 . The second phase of development would begin on January 1, 1987 and extend to June 30,1987 . Subsequent phases would encompass six-month periods thereafter, through June 30, 1991.

Status of data elements. In any phase, each data element that will ultimately be a part of the national data system can be characterized as belonging to one of three categories of development. At one extreme, would be data elements that are not yet included in any form. An intermediate category would be data elements that were collected only in aggregate form; e.g. , school membership determined from a report prepared by a school. Note that we do not propose to develop such aggregate reports, only to maintain specific elements that are currently a part of critical NCES data-collection activities, until they could be replaced by tested and verified microrecords. These microrecords would constitute the third category (that is, the other extreme of development) of data elements. Currently, such microrecords only exist in data projects such as NAEP or NELS.

Availability of data elements. We believe that most, if not all, of the data collection formats for elements required in early phases of implementation of the system already exist within current Center data programs (e.g., NAEP or NELS). Development of data collection formats and activities incorporating such data elements formats would be required to implement the system, but more fundamental 'research' activities would not. At any phase of development, however, a data element that existed in microrecord form might not yet be available for operation use. Initially, some such microrecord data elements would require extensive research and development. Once a data element has been newly developed, it would be subject to extensive field testing and verification; that is, a new data element in microrecord form would not become a part of the operational data system until convincing evidence of its validity and utility has been amassed. Only after the validity, utility, and feasibility of collecting a data element in microrecord form had been demonstrated, would that element be available as an operational part of the national data system.

Linkage among data files. As the different sets of data elements become available for operational use, linkages among these sets must be established, tested, and verified. The testing and verification also must include assessments of the relative utility of the relational policy analyses generated from the linked data sets. These assessments must continue and encompass the increasingly larger number of linked data sets that come on line as additional microrecords become operational, until the national data system becomes fully operational.

Concurrent development activities. Although we will not elaborate here, implicit in the research, development, testing, and verification activities noted above are such data system design and development activities as the identification of essential populations of generalization; the design and selection of samples of data suppliers; the design of 
mechanics for collection of data, including specifications for, recruitment of, and training of data collectors; the design of survey field procedures; the design of plans for analysis of data and reporting of results; the development of systems for transmission of data; and the development of software systems for data receipt, control, editing, analysis, and summarization.

In the following table, we provide a truncated outline which is illustrative of the development and phasing activities discussed above. For example, under the category 'Environment' we identify the subcategory 'community and family characteristics' and indicate that, at the present time, data in this subcategory are collected only in aggregate form in the data collection activities currently being conducted by the Federal Center for Statistics. In Phase I, research and development activities would be undertaken, in Phase II, testing and verification would take place, and in Phase III, the data would become available in microrecord form. The reminder of Table 7.1 can be read in the same fashion; in the subcategory 'school goals', for example, research and development activities would not begin until Phase III, whereas in the subcategory 'dropouts' - where data in aggregate form already are being collected - research and development activities would begin immediately in Phase 1. Note that Table 7.1 illustrates only the first three of ten proposed development phases.

Table 7.1

Illustrative Status of Categories and Subcategories of Data at Various Phases of Development of the National Data System

\begin{tabular}{|c|c|c|c|c|}
\hline \multirow{2}{*}{ Categories and subcategories } & \multirow{2}{*}{ Current } & \multicolumn{2}{|c|}{ Status of Data Category } & \multirow[b]{2}{*}{ Phase III } \\
\hline & & Phase I & Phase II & \\
\hline $\begin{array}{l}\text { Environment } \\
\text { Family and community } \\
\text { characteristics }\end{array}$ & Ag. & Ag.(R\&D) & Ag.(T\&V) & Micro \\
\hline $\begin{array}{l}\text { Resources } \\
\text { Financial revenues }\end{array}$ & Ag. & Ag. & Ag.(R\&D) & Ag.(T\&V) \\
\hline $\begin{array}{l}\text { Educative difficulties } \\
\text { Handicapped status } \\
\text { Motivation }\end{array}$ & $\begin{array}{l}\text { Ag. } \\
\text { Non. }\end{array}$ & $\begin{array}{c}\text { Ag.(R\&D) } \\
\text { Non.(R\&D) }\end{array}$ & $\begin{array}{c}\text { Ag.(T\&V) } \\
\text { Non.(R\&D) }\end{array}$ & $\begin{array}{c}\text { Micro } \\
\text { Non.(T\&V) }\end{array}$ \\
\hline $\begin{array}{l}\text { Educative goals } \\
\text { School goals }\end{array}$ & Non. & Non. & Non. & Non.(R\&D) \\
\hline $\begin{array}{l}\text { Participation } \\
\text { Course enrollment }\end{array}$ & Micro. & Micro.(R\&D) & Micro.(T\&V) & Micro.(Rev). \\
\hline $\begin{array}{l}\text { Outcomes } \\
\text { Dropouts }\end{array}$ & Ag. & Ag.(R\&D) & Ag.(T\&V) & Micro. \\
\hline
\end{tabular}

Non. denotes a data subcategory that does not presently exist in the set of projects operated by the Federal Center for Statistics.

$\mathrm{Ag}$. denotes a data subcategory in which data are presently collected only in aggregate form in the set of projects operated by the Federal Center for Statistics.

Micro. denotes a data subcategory in which data are presently collected in the form of microrecords in the set of projects operated by the Federal Center for Statistics.

(R\&D) denotes a data subcategory in which research and development is to be conducted.

(T\&V) denotes a data subcategory in which testing and verification is to be conducted.

(Rev.) denotes a data subcategory in which the data previously existed in the form indicated, but for which revised data elements are developed and adopted. 
Establishing priorities for development. Table 7.1 is only illustrative of the types of decisions that would have to be made in developing a national data system for elementary and secondary education. The actual choices of the order in which categories and subcategories of data elements would be developed must be made by the Federal Center for Statistics, the Office of Educational Research and Improvement, and the consortium of local, state, and federal agencies described below. However, based on our intensive and careful review of the needs expressed by authors of the papers underlying the Synthesis Report, we proposed consideration of the following priorities.

The conceptual model and data base design that are defined in 'Designing a New National Educational Information System' provide categories of data that are required to meet the information needs of education policy-makers at several levels of government, as well as those of the new constituencies for information identified in other parts of this report. Of all data categories defined by that model, school process information is least available now. School process information includes: information on the educative goals of the schools; on allocated resources - facilities, staff, equipment and materials; information on educational pursuits - curricular offerings, standards, teaching-related and school-related activities; and information on pupil participation in the process of schooling. There is also a critical need for high quality outcome data. The best outcome data available are presently provided by NAEP. However, these data are limited to students at relatively few grade levels, are only collected biannually, and are limited in subject matter tested. Therefore, in our judgment, two categories of data - school process data and outcome data deserve priority in the development of the national data system. However, although information on process and outcome have the highest priorities in terms of need as a practical matter the data system should attempt first to develop microrecords on a small subset of data to develop the collection process and refine the data base development process. Information on pupil participation which would provide data for enrollment and attendance would be priority candidate for initial development. The research effort to develop a more comprehensive set of process and outcome data should be given high priority and proceed on a parallel track.

School context information should constitute a third area of priority development; particularly information that describes the environment in which the schools operate, such as community and family characteristics and expectations, as well as information that describes the educative difficulties of students. In our judgement, these two categories of data should receive attention once the development of microrecords is well underway in the school process and outcomes categories.

Our fourth order of priority would be to address data needs in the educative goals category. A final priority, but certainly essential, would be the categories of incoming and allocated resources, including revenues, and expenditures for, and stocks of, materials, equipment, facilities, and personnel. As is clear from Table 7.1 above, certain existing aggregates are recommended for phasing into microrecord formats stages beyond Phase $\mathrm{I}$. This raises the issue of parallel aggregate reporting for existing aggregate data series to allow users to move from the old problematic series to the microrecord based series. This overlap should be carefully planned into the phasing of the new system.

Description and timing of the development and phasing of state involvement in the national data system. For the data system to be truly national, states must be involved in each phase of the development and maintenance of the system. One of the challenges to 
the Federal Center will be to ensure that this kind of state participation actually takes place.

The Department of Education has already begun to involve state governments in the process. Copies of the Synthesis of Invited Papers which were commissioned to examine the needs for a new national data system for elementary and secondary education have been sent to each of the governors, the leadership and education committees of the state legislatures, the chief state school officers, and the various associations of state entities. Copies of an early draft of the full report on which this article is based were also made available to staff members of some of the same associations for comment. Once the final decision is made to implement a new system, a formal federal/state mechanism must be established to plan and monitor the development of the national system.

A first step will be the establishment of a consortium to provide the planning mechanism. This consortium would be made up of representatives of the state governments as well as selected representatives of private school groups, persons from academia, representatives from the Department of Education and others interested in education. The consortium would be established through invitations sent by the Department to each state. The governors, legislative leaders and the chief state school officers of each would be involved in the selection of a representative of that state to the consortium. At the same time the Department would nominate members who would be able to represent the views of other data providers and data users.

It is expected that the consortium will be appointed in the first quarter of 1986, and could have its organizing meeting in April. In preparation for the consortium's first meeting, the Center would prepare a draft agenda which would be circulated to the membership for comments.

The first major task of the consortium would be to select a committee to consider specific information requirements and recommend development and phasing priorities, with special attention to the standardization of data definitions for the system. This activity would be timed to coincide with and become part of the development and phasing effort described above. The Committee would consist of persons selected by the consortium as well as appropriate ex officio members of the staff of the Center for Statistics and other parts of the Department of Education. The committee as well as the consortium would be staffed by the Center.

There are several states which are now seriously considering the development of integrated management information systems. Another committee could be established, composed of the appropriate technical personnel from some or all of those states, to review the progress being made by each, and to attempt to develop common features which could then provide data to the Center under the provisions of Alternative B. Depending on the number of states involved, a limited number of 'observer' states could participate in this effort.

The consortium would also consider other issues and establish such committees as are required to carry out its work, within the limits of the Center's ability to provide support.

It is expected that the full consortium would meet no more frequently than once a year. However, the committees would meet on an as needed basis and prepare reports which would be reviewed and approved by the membership and published as technical assistance for others. 


\section{Impact and Benefits of the New System}

\section{Effects on Existing Data Programs}

Regardless of the levels of involvement of individual states, development of a new national data system on elementary and secondary education will substantially affect current data collection, analysis and reporting activities in state education agencies, in local education agencies and in the U.S. Department of Education.

Impact on federal programs. As noted earlier, a new data system will require dollar resources and personnel currently allocated to ongoing federal projects and will impose respondent burdens that will preclude the continuation of numerous existing federal datacollection projects and the initiation of others. Issues such as these transcend the selection of a data system design, and influence the phasing and timing of data system development and installation. The most pertinent of these issues are:

(1) Preservation of essential data time series.

(2) Requirements for research needed to develop critical elements of the new data system.

(3) Provision of adequate time for data system testing and verification.

(4) Impact on current state and local education agency data systems.

(5) Cost and personnel requirements of various phases, by level of government.

Preservation of essential data time series. Although this report has identified many inadequacies in the present national data system on elementary and secondary education, the Federal Center for Statistics has, nevertheless, maintained several essential data time series. Examples of such time series can be found in the Center's Publications The Condition of Education and the Digest of Educational Statistics, and include, by way of illustration, total enrollments at all levels of education throughout the United States, which have been reported since 1899-1900 (Digest of Educational Statistics, 1983-84, Table 3, p. 8). Such time series must be preserved in the new national data system.

Impact on current state and local education data systems. The burden imposed by the new data system on state education agencies will vary, depending on an individual state's level of participation. At one extreme, if a state chose to keep its own data systems completely separate from the national data system, no additional data burden would be imposed, nor would the state be required to adapt its data-element definitions to be coincident with those of the national system. At the other extreme, if a state chose to fully integrate its data systems with the national system, it would have to accept and adopt the data-element definitions used in the national system, and it would have to adopt the microrecord structure that is central to the national data system. In addition, in some of the smaller states, the proposed national data system will likely collect data in a substantial proportion of the states' local education agencies. Therefore the response burden imposed by the national data system might limit the data-collection options of the state education agencies in these states.

The impact of the national data system will be limited to those local education agencies that are included in the state-representative samples used by the system. In sampled local education agencies, the volume and density of data collection envisioned for the national 
system will represent substantial data burden, and will likely require local agencies to adapt their own data systems in several ways. For example, the local education agencies might choose to make the data element definitions they use consistent with those of the national system. Local agencies might also choose to make the structure of their data systems consistent with the microrecord structure of the national system. Although such modifications would not be mandatory, they would help to minimize respondent burden and to maximize data-collection efficiency. And, of course, in states that chose to integrate their data systems with the national system, these impacts would not be limited to a sample of local education agencies, but would apply to all of the states' local agencies.

\section{Needs and Issues Addressed by the System}

The current national data system in elementary and secondary education - as we discussed in 'What should be the Federal Role in Building a National Information System' above - is piecemeal and fragmented. We have very little information about the family backgrounds and educative difficulties and characteristics of pupils and the little we have is collected sporadically and exists in data sets which are rarely linked to resources, participation, and outcomes. We have basic information on revenues, expenditures by accounting category, and educational personnel. But these data are not linked together in ways which allow the tracing of resources flows. Outcome data are extensive in some data bases (e.g., the National Assessment of Educational Progress and state assessment programs), but these data are not linked to data about program offerings or participation in any cohesive fashion. Participation data (e.g. , from the National Education Longitudinal Studies, or the Survey of Income and Program Participation) are not effectively linked to institutional data on expenditure or personnel.

The virtue of an integrated national educational information system built around a comprehensive conceptual framework lies in guaranteeing that the central priorities for data are met. This framework helps deliniate the data content to be included and the setting of priorities concerning that content. However, some of the most important aspects of a new data system relate to its ability to address the new needs discussed in 'Capabilities of Present Education Data Systems'. These needs primarily relate to using a new information system to address service delivery, and the linkage of delivered services to resources, pupils, and outcomes. From this perspective it becomes clear that the linkages between data elements are just as important as the existence of particular elements and the degree to which they comprehensively and validly represent a particular aspect of the educational system. In the examples below, we illustrate some of these linkage issues.

Quality and effectiveness of educational systems. Above we made the point that achievement, although central to the assessment of educational quality is not sufficient. First, one cannot adequately evaluate achievement as an index of effectiveness without knowing to which goals the system is directed. It is the discrepancy between desired outcomes - goals - and actual outcomes which diagnoses the effectiveness of the system. To the extent that systems are directed to different goals or have different distributions of planned outcomes, they cannot be validly evaluated without knowledge of their goals. In addition, even such holistic evaluations of quality must take into account the educative difficulties which the system faces. For example, schools, districts, and even state educational systems serve pupils of widely varying linguistic backgrounds, parental supports and resources. These 
discrepancies will lead to different outcomes even when system goals and resources are similar. This implies that goals, pupil characteristics - backgrounds, difficulties - and resources must be linked to each other and to outcomes in order to assess quality and effectiveness.

Also, if we are to probe quality and effectiveness so as to give guidence for change, these linkages must also be made at the microlevel, i.e., the record structure must allow resources to be linked to personnel, personnel to be linked to services, and services to be linked to pupils and their achievements.

Resource flows. One of the central data needs not currently met by the existing data system is resource flow information. The fragmented data collection system produces information on revenue sources, expenditure categories, and personnel, but these information components are not linked in such a way that one can tell which monies are spent on what. A part of the 'problem' is in the fund accounting system of most school districts. However, the major issue resides in the lack of linkage between the accounting categories used for expenditure reporting and their (lack of) articulation with personnel categories reported. A system must be designed to allow micro linkages of accounting system expenditures to personnel records and employee characteristics. Additionally, these records and characteristics must be linked to the experiences and services offered in the district and (ultimately, see below) to pupils.

Pupil participation. The fundamental requirement for assessing both the equity and effectiveness of educational programs is information on who participates. Equity, at its root, has to do with social and legal determinations of the amounts of resources and the kinds of programs which should be mounted for particular categories of pupils to meet their needs and to fulfill society's responsibilities to them. The data problem is made more difficult by the fact that educational agencies mount quite different programs, requiring different amounts of resources, and resulting in differential participation, by pupils of different types. Fundamentally, one would like to know:

(a) the quantity of resources and the characteristics of programs and experiences participated in by various kinds of pupils; and

(b) the outcomes of pupil participation by both pupil and program or service characteristics.

These kinds of relationships require linkage of service characteristics with pupil characteristics via participation information. These linkages, in turn, require microdata on individuals.

Productivity and efficiency. Quality and effectiveness are not the same as productivity or efficiency. The former terms refer to outcomes of a system in relation to its goals and the difficulties it faces. Productivity and efficiency relate quality and effectiveness to the resources used to mount educational efforts. To the extent that one educational system is of the same quality or effectiveness as another, but has used fewer resources to accomplish this, it is more productive or efficient. Thus, to evaluate productivity or efficiency one needs to link resource information to outcomes, via goals, difficulties, services and participation. In this sense, the microrecord structure and data collection needed to support analyses of educational productivity and efficiency are the most stringent of all. They re- 
quire information on all three of the above topics: quality and effectiveness, resource flows, and pupil participation.

\section{Some Benefits of the System}

The consumers of information about educational systems include parents concerned about the education of their children, citizens worried about the quality and efficiency of the education their tax dollars finance, professional educators making decisions about programs and pupils, and public officials desiring to design laws, requirements, and resource allocations which will effectively improve education. All of these consumers are concerned that the information which reaches them be relevant and useful to their needs, timely, and accurate.

Common to all of the consumers are concerns about quality and effectiveness. It is this information which is most desired in the public debate over education. Parents want to know about the quality of education their children receive and about the qualities of the educational alternatives available to them. Citizens and public officials wish valid assessments of efficiency to know that resource allocations are wisely made and carried through desired outcomes.

Resource flows are important information for public officials in making determinations of how much and how to allocate resources. Federal officials have special concern for how federal resources are channeled to pupils and the impact of these resources on pupils with specific characteristics. State officials, in fulfilling their responsibilities, have been modifying state educational systems in ways that require comprehensive information about participation in programs, courses, and other services, standards of performance and actual outcomes. Local officials are newly concerned that they are effectively monitoring service delivery, participation and achievement.

An effectively integrated system - incorporating the microdata and records necessary to produce these new types of information - is needed by all concerned parties. The benefits of a cohesive system of this type producing national and state comparable data would be far reaching. Not only would the majority of consumers of educational information be provided with relevant, integrated, timely, and accurate information at these two levels, but the establishment of such a system would produce similar changes in district-level information systems. This, in turn, would increase the comprehensiveness and comparability of the information about education taking place in local communities. Thus, the national information system, as it is established at state and national levels will introduce cohesion in the total system.

\section{References}

Anrig, G. R. (1985). Teacher education and teacher testing: The rush to mandate. Paper presented at the Annual Meeting of the American Association of Colleges for Teacher Education, Denver, CO.

Banner, I. M., Jr. (1985). Revising educational statistics. National Center for Education Statistics Redesign Project. Washington, D.C.: National Center for Education Statistics.

Barro, S. M. (1985). An assessment of NCES data collection efforts in two areas: School finance and teachers. National Center for Education Statistics Redesign Project. Washington, D.C.: National Center for Education Statistics.

Benjamin, R. (1981). Making schools work: A reporter's journey through some of America's most remarkable classrooms. New York: Continuum. 
Berger, P. L., \& Neuhaus, R. J. (1977). To empower people: The role of mediating structures in public policy. Washington, D.C.: The American Enterprise Institute.

Berryman, S. E. (1985). Education and employment: Substitution possibilities and the teacher labor force: Supply and demand. National Center for Education Statistics Redesign Project. Washington, D.C.: National Center for Education Statistics.

Bishop, J. H. (1985). Data collection for improving elementary/secondary education. National Center for Education Statistics Redesign Project. Washington, D.C.: National Center for Educational Statistics.

Boyer, E. L. (1983). High school: A report on secondary education in America. New York: Harper \& Row.

Coleman. J. (1985). Data needs for school policy in the next decade. National Center for Education Statistics Redesign Project. Washington, D.C.: National Center for Education Statistics.

Coleman, J., \& Karweit, N. (1972). Information systems and performance measures in schools. Englewood Cliffs, NJ: Educational Technology Publications.

Cooke, C., Ginsburg, A., \& Smith, M. (1985). Researchers find that education statistics are in a sorry state. Basic Education, 29, 3-8.

Committee on Economic Development. (1985). Investing in our children: Business and the public schools. Washington, D.C.: Author.

Council of Chief State School Officers. (1985). Comments of the Council of Chief State School Officers on the National Center for Education Statistics Redesign of the Elementary and Secondary Education Data Program. National Center for Education Statistics Redesign Project. Washington, D.C.: National Center for Education Statistics.

Cronin, J. M. (1985). Issues in national educational data collection. National Center for Education Statistics Redesign Project. Washington, D.C.: National Center for Education Statistics.

David, J. L. (1985). Improving the quality and utility of NCES data. National Center for Eduation Statistics Redesign Project. Washington, D.C.: National Center for Education Statistics.

Doyle, D. P., \& Levine, M. (1985). Business and the public schools: Observations on the policy statement of the Committee for Economic Development. Phi Delta Kappan, 67(2).

Education Commission of the States. (1983). Action for excellence: Report of the task force for education on economic growth. Denver, $\mathrm{CO}$ : Author.

Eubanks, E. E. (1985). Data needs for big city schools. National Center for Education Statistics Redesign Project. Washington, D.C.: National Center for Education Statistics.

Fuhrman, S., \& Rosenthal, A. (1981). Shaping education policy in the states. Washington, D.C.: The Institute for Educational Leadership.

Grant, W. V. (1985). An elementary and secondary school statistics program for the National Center for Education Statistics. National Center for Education Statistics Redesign Project. Washington, D.C.: National Center for Education Statistics.

Hannaway, J. (1985). Two suggestions for NCES data collection. National Center for Education Statistics Redesign Project. Washington, D.C.: National Center for Education Statistics.

Harnischfeger, A. \& Wiley, D. E. (1985). Quality of Education: Conception and Assessment. Kenilworth, IL.: Beacon Institute.

Harrison, F. W. (1985). Review of elementary/secondary school data needs of the National Center for Education Statistics. National Center for Education Statistics Redesign Project. Washington, D.C.: National Center for Education Statistics.

Hawley, W. D. (1985). Educational statistics and school improvement. National Center for Education Statistics Redesign Project. Washington, D.C.: National Center for Education Statistics.

Hersh, R. H. (1985). Organizational efficacy as a research focus for school improvement. National Center for Education Statistics Redesign Project. Washington, D.C.: National Center for Education Statistics.

Hilliard, A. G., III. (1985). Information for excellence and equity in education. National Center for Education Statistics Redesign Project. Washington, D.C.: National Center for Education Statistics.

Jaeger, R. M., \& Tittle, C. K. (Eds.) (1980). Minimum competency achievement testing. Berkeley. CA: McCutchan.

Kursch, H. (1965). The United States Office of Education: A century of service. Philadelphia, PA: Chilton Books.

Lehnen, R. G. (1985). Educational statistics for studies of policy and administration. National Center for Education Statistics Redesign Project. Washington, D.C.: National Center for Education Statistics.

McClure, M., \& Plank, D. N. (1985). Educational statistics for educational policy: A political economy perspective. National Center for Education Statistics Redesign Project. Washington, D.C.: National Center for Education Statistics.

Miller, L. (1985). A house of bricks. National Center for Education Statistics Redesign Project. Washington, D.C.: National Center for Education Statistics.

Murnane, R. J. (1985). Priorities for federal education statistics. National Center for Education Statistics Redesign Project. Washington, D.C.: National Center for Education Statistics.

National Commission on Excellence in Education. (1983). A Nation at risk: The imperative for educational reform. Washington, D.C.: U.S. Government Print Office. 
Natriello, G. (1985). Products and processes of the National Center for Education Statistics: An agenda for the next decade. National Center for Education Statistics Redesign Project. Washington, D.C.: National Center for Education Statistics.

New York Stock Exchange. (1982). People and productivity: A challenge to corporate America. New York: Author.

Odden, A. (1985). Federal collection of school finance data: New needs for an era of education reform. National Center for Education Statistics Redesign Project. Washington, D.C.: National Center for Education Statistics.

Peterson, P. L. (1985). The elementary/secondary redesign project: Assessing the condition of education in the next decade. National Center for Education Statistics Redesign Project. Washington, D.C.: National Center for Education Statistics.

Pierce, N. W. (1977 December 13). An 'Educational Bill of Rights?' The Washington Post.

Pipho, C. (1984). State competency testing programs. Denvo, CO: Education Commission of the States.

Plisko, V. W., Ginsburg, A., \& Chaikind, S. (1985). Assessing national data on education. National Center for Education Statistics Redesign Project. Washington, D.C.: National Center for Education Statistics.

Reisner, E. R. (1985). New areas for educational data collection: What students are taught and what they learn. National Center for Education Statistics Redesign Project. Washington, D.C.: National Center for Education Statistics.

Rosenholtz, S. J. (1985), Needed resolves for educational research. National Center for Education Statistics Redesign Project. Washington, D.C.: National Center for Education Statistics.

Scott-Jones, D. (1985). Assessing American education: Shrinking resources, growing demands. National Center for Education Statistics Redesign Project. Washington, D.C.: National Center for Education Statistics.

Selden, R. W. (1985). Educational indicators: What we need to know that we don't know now. National Center for Education Statistics Redesign Project. Washington, D.C.: National Center for Education Statistics.

Thomas, G. E. (1985). Issues and considerations for a ten-year program on elementary and secondary school data collection. National Center for Education Statistics Redesign Project. Washington, D.C.: National Center for Education Statistics.

Twentieth Century Fund. (1983). Making the grade: Report of the Twentieth Century Fund task force on federal elementary and secondary education policy. New York: Author.

Usdan, M. D. (1985). Educational data needs for the balance of the 20th century: Some perspectives on the emerging environmental context. National Center for Education Statistics Redesign Project. Washington, D.C.: National Center for Education Statistics.

Valdivieso, R. (1985). Hispanics and educational data. National Center for Education Statistics Redesign Project. Washington, D.C.: National Center for Education Statistics.

Walberg, H. J. (1985). National statisties for improving educational productivity. National Center for Education Statistics Redesign Project. Washington, D.C.: National Center for Education Statistics.

\section{Biographies}

George E. Hall is President of Slater Hall Information Products which is involved with utilizing the latest technology to make large scale data sets available on micro-computers for researchers. He is also the chief executive of Baseline Data Corporation, a statistical consulting firm. Prior to that he was a senior statistician for the U.S. Federal Government in such roles as Associate Director of the Bureau of the Census, the Deputy Director of the Office of Federal Statistical Policy and Standards (OFSPS), and Assistant Administrator (statistics and information systems) of the Law Enforcement Assistance Administration. While at OFSPS he had oversight over all federal social and demographic statistics programs including education; similarly, at the Census Bureau, he was responsible for all of the social and demographic statistics programs including the decennial census.

Richard M. Jaeger is Professor, Coordinator of Graduate Programs in Educational Research and Evaluation, and Director of the Center for Educational Research and Evaluation at the University of North Carolina at Greensboro. He is President of the National Council on Measurement in Education, past Editor of the Journal of Educational Measurement, and a member of numerous technical advisory boards concerned with educational and professional testing. His recent books include Sampling in Education and the 
Social Sciences (Longman, 1984) and Statistics: A Spectator Sport (Sage, 1983). He received his $\mathrm{Ph} . \mathrm{D}$. in educational research methodology from Stanford University.

C. Philip Kearney is Professor of Education and Director of the Bureau of Accreditation and School Improvement Studies, School of Education, The University of Michigan, where he has been a faculty member since 1980 . From 1977 to 1980 , Kearney served as Associate Director and then Deputy Director of the Institute for Educational Leadership in Washington, D.C. For 9 years prior to that, he was with the State of Michigan as Associate Superintendent of Public Instruction. His current interests center on the relationships between public policy decisions and educational improvement, particularly governance and finance decisions at state and national levels. Kearney holds B.A. and M.A. degrees from the University of Portland in Oregon, and a Ph.D. from the University of Chicago.

David E. Wiley is Professor and Dean of the School of Education and Social Policy, Northwestern University. He is currently a member of the Research and Evaluation Advisory Council of the Illinois State Board of Education; the Technical Advisory Committee of the California Assessment Program; and the Committee on Research in Mathematics, Science, and Technology Education of the National Research Council. He has been a resident advisor to the Venezuelan Ministry of Education and Fellow, Center for Advanced Study in the Behavioral Sciences. He has been a visiting research scholar at the Ontario Institute for Studies in Education; The International Association for the Evaluation of Educational Achievement; and the Max-Planck-Institute für Bildungsforschung. His specializations include cducational testing and evaluation, social policy, and statistics. 